\title{
Midlatitude ocean-atmosphere interaction in an idealized coupled model
}

\author{
S. Kravtsov ${ }^{1}$ and A. W. Robertson ${ }^{2}$ \\ Department of Atmospheric Sciences and \\ Institute of Geophysics and Planetary Physics \\ University of California, Los Angeles \\ 405 Hilgard Ave. \\ Los Angeles, CA 90095-1565
}

Climate Dyn., accepted

March 18, 2002

${ }^{1}$ Corresponding author email: sergey@atmos.ucla.edu

${ }^{2}$ Current address: International Research Institute for climate prediction (IRI), Monell Building, room 230, P. O. Box 1000, Palisades, NY 10964-8000 


\section{Abstract}

Interannual-to-interdecadal ocean-atmosphere interaction in midlatitudes is studied using an idealized coupled model consisting of eddy-resolving two-layer quasi-geostrophic oceanic and atmospheric components with a simple diagnostic oceanic mixed layer. The model solutions exhibit structure and variability that resemble qualitatively some aspects of the observed climate variability over the North Atlantic. The atmospheric climatology is characterized by a zonally modulated jet. The single-basin ocean climatology consists of a midlatitude double jet that represents the Gulf Stream and Labrador currents, which are parts of the subtropical and subpolar gyres, respectively.

The leading mode of the atmospheric low-frequency variability consists predominantly of meridional displacements of the zonal jet, with a local maximum over the ocean. The first basinscale mode of sea-surface temperature has a red power spectrum, is largely of one polarity and bears qualitative similarities with the observed interdecadal mode identified by Kushnir (1994). A warm sea-surface temperature anomaly is accompanied by anomalously low atmospheric

pressure, an intensified model Gulf Stream and a weakened Labrador current. This mode is found not to be affected significantly by oceanic coupling.

In the western part of the basin, this sea-surface temperature pattern is shown to be forced by the slowest components of the surface-wind anomaly through a delayed modulation of the baroclinic time-dependent boundary currents which advect mean SST, with synchronous variations in the two oceanic jets. The response in the east is found to be dominated by local atmospheric forcing.

Basin-scale intrinsic oceanic variability consists of a damped oceanic oscillatory mode in the baroclinic flow field that is excited by the atmospheric noise. Its period is around 5.5 years, but it has a negligible influence on the evolution of sea-surface temperature. Important for this mode's excitation is the meridional position of the atmospheric center of action relative to the ocean gyres. 


\section{Introduction}

Ocean-atmosphere interaction in midlatitudes is a potential source of interannual-tointerdecadal climate predictability, based on the midlatitude ocean's long intrinsic time scales. However, the existence of significant coupled modes of variability has not been unambiguously established. In this paper, we investigate interactions between the wind-driven ocean gyres and modes of midlatitude atmospheric variability using a coupled model of intermediate complexity.

Such modeling studies provide a means of isolating the roles of processes intrinsic to either the atmosphere or ocean, versus the coupling between them. Steadily forced eddy-resolving models can themselves generate vigorous internal oceanic variability with interannual and interdecadal time scales (e.g., Cessi and Ierley 1995; Ierley and Sheremet 1995; Berloff and McWilliams 1999). In the weak friction limit, modeled oceanic internal variability crucially depends on the ability of the model to capture baroclinic instability (Meacham and Berloff 1997a,b; Berloff and Meacham 1997,1998; Dijkstra and Katsman 1997; Ghil et al. 2002). The difference between the reduced-gravity and two-layer models comes primarily from the changes in the inertial recirculation dynamics when baroclinic eddies are included (e.g., Spall 1996). Simple coupled models have tended to support the importance of ocean dynamics in determining midlatitude SST variability (Liu 1993; Jin 1997; Weng and Neelin 1998; Münnich et al. 1998; Cessi 2000). However, these models have been limited to linear one-layer or reducedgravity oceans coupled to ad hoc or highly simplified atmospheric parameterizations.

General circulation model (GCM) studies have given conflicting results, providing no consensus as to whether coupled modes of midlatitude variability are important or not. Some of them produce behavior interpreted as a coupled mode (Latif and Barnett 1994, 1996; von

Storch 1994; Robertson 1996; Grötzner et al. 1998). Others suggest that midlatitude coupling is of limited importance to decadal climate variability (Kushnir and Lau 1992; Ferranti et al. 1994; Peng et al. 1995; Saravanan 1998; Danabasoglu 1998; Saravanan et al. 2000; Robertson 2001; Schneider et al. 2002).

The aim of this study is to fill the gap between the rather ad hoc simple coupled models of midlatitude ocean-atmosphere interaction, and GCMs. The model of intermediate complexity consists of an eddy-resolving two-layer quasi-geostrophic $(\mathrm{QG})$ ocean in a rectangular basin representing the North Atlantic ocean, coupled to a two-layer channel QG atmosphere. An 
explicit diagnostic oceanic mixed layer is included. This is the first time, to our knowledge, that a simple eddy-resolving ocean model has been coupled to a dynamically consistent atmospheric model. Thus, the model is one of the simplest midlatitude-climate process models that retains a fairly complete set of the relevant physics. The quasi-geostrophic formulation in the atmosphere is implemented to describe both the climatology and variability around it, which allows us to use a specified heat flux at the top of the atmosphere as the natural forcing function of the climate. Diabatic physics is also explicitly included in the quasi-geostrophic ocean. However, a lot of potentially important physics is simply missing from the model: the geometry is highly simplified, there is only one ocean basin, there is no topography on land, the land model itself is very crude, etc. These will have an effect on the model climate, making it different from what is inferred from observations. Nevertheless, we believe that of primary importance in understanding the system as complicated as climate is to concentrate on dynamically consistent subsets of the full physics, followed by incremental conceptual drift towards realism. This motivates our strategic choice of an idealized model, not meant to reproduce reality, but rather to point to potentially important generic properties associated with the resolved dynamics. It would be possible then to seek for the traces of such properties in observations of the real climate system.

Joint evolution of the oceanic and atmospheric components of the midlatitude climate involves many feedbacks, which may operate differently depending on the temporal and spatial scales of the system's evolution (e.g., Marotzke and Pierce 1997). On interannual time scales sea-surface temperature (SST) anomalies over the North Atlantic are known to be largely driven by the atmosphere through anomalous surface heat fluxes and shallow Ekman currents (Bjerknes 1964; Wallace et al. 1990). These lead to the well-known SST tripole pattern over the North Atlantic (Deser and Blackmon 1993) that accompanies the North Atlantic Oscillation (NAO) in atmospheric sea-level pressure (SLP). Here, zonally banded SST anomalies bear a direct local relationship with the surface winds, because negative SST anomalies are generated by anomalously strong westerlies though enhanced evaporation and anomalously southward Ekman currents, and vice versa.

On interdecadal time scales, however, the observed SST pattern lacks this distinctive local relationship with the surface winds, suggesting a coupled mode (Bjerknes 1964; Kushnir 1994). 
The SST difference pattern between 1950-1964 (warm years) and 1970-1984 (cold years) has positive polarity over most of the North Atlantic ocean, except near the western boundary between the Gulf Stream and the Labrador currents $(35-45 \mathrm{~N})$ where there is a strong local cold anomaly (Kushnir 1994). There are two primary positive SST anomalies, located northeast of Bermuda and in the Labrador Sea respectively. This pattern is accompanied by an anomalously low SLP center over the mid Atlantic at about 45N, such that interdecadal warming south of $45 \mathrm{~N}$ is associated with enhanced surface westerlies. Similar observations in earlier decades lead Bjerknes (1964) to the hypothesis that this type of interdecadal warming is linked to a basinscale interaction in which the Gulf Stream responds to an intensifying subtropical anticyclone. It has since been found that temperature anomalies in the upper $1000 \mathrm{~m}$ of the ocean exhibit a similar spatial structure (Levitus 1989a,b) and are accompanied by changes in the intensity of the Gulf Stream (Greatbatch et al. 1991), lending further credence to the ocean's active role.

In the linear theory of the atmospheric response to a low-level heating anomaly in midlatitudes, a baroclinic surface cyclone is forced downstream of the heating so as to balance the heating by meridional advection. On the basis of a qualitative similarity to linear theory, Kushnir (1994) suggested that the concurrent mid-basin anomalously low SLP described in the previous paragraph could be a baroclinic response of the atmosphere to a heat source over the Labrador Sea, so that the ocean may drive the atmosphere on the interdecadal time scales in the North Atlantic region. Kushnir and Held (1996) provide supporting evidence for this view using a coarse-resolution GCM, while also pointing out that the evidence from atmospheric GCM studies is often contradictory. More recently, large ensembles of GCM experiments by Rodwell et al. (1999) and Mehta et al. (2000) have provided more convincing evidence of oceanic forcing over the North Atlantic.

In this paper, we attempt to develop a conceptual understanding of how the coupled feedbacks might work, if at all, on the interdecadal time scale in a model much simpler than reality. We will provide a demonstration of how a simple pattern of atmospheric variability induces a spatially complex SST response via different processes operating in different parts of the basin. One of our goals is address the potential for oceanic eddies to play an important role in midlatitude climate variability. After discussing the model formulation in Section 2, we start by investigating the uncoupled variability that is intrinsic to the atmosphere and ocean compo- 
nents separately in Section 3. The models are then coupled together in Section 4. Here we find that the behavior of a coupled model differs little from that of the ocean-only run forced by the atmospheric history from the coupled integration, and the atmospheric behavior is virtually identical to that of the atmosphere-only model forced by fixed SSTs. The effect on the model atmosphere of prescribing a leading SST anomaly from the coupled run is shown to be weak. The summary and discussion can be found in Section 5 .

\section{Model Formulation}

Our model is a simplified version of that developed by Dewar (2002). The equations governing the dynamical modules of the model are two layer quasi-geostrophic (e.g., Pedlosky 1987), using high resolution of $160 \mathrm{~km}$ in the atmosphere and $10 \mathrm{~km}$ in the ocean.

\subsection{Model geometry}

The model geometry is depicted in Fig. 1, with a vertical cross-section through the model on the top and a plan view shown in the bottom panel. The ocean basin is meant to represent a midlatitude portion of the North Atlantic ocean and extends longitudinally from $X_{\mathrm{W}}=3520 \mathrm{~km}$ to $X_{\mathrm{E}}=8640 \mathrm{~km}$ (approximately $60^{\circ}$ wide at $45^{\circ} \mathrm{N}$ ) and latitudinally from $Y_{\mathrm{S}}=-3200 \mathrm{~km}$ to $Y_{\mathrm{N}}=2400 \mathrm{~km}\left(16^{\circ} \mathrm{N}\right.$ to $\left.66^{\circ} \mathrm{N}\right)$ with $y=0$ corresponding to the $45^{\circ} \mathrm{N}$. Atmospheric latitudinal boundaries are situated at $Y_{\mathrm{a}, \mathrm{S}}=Y_{\mathrm{S}}$ and $Y_{\mathrm{a}, \mathrm{N}}=3200 \mathrm{~km}$, i.e., at $16^{\circ} \mathrm{N}$ and $74^{\circ} \mathrm{N}$ respectively. The longitudinal atmospheric boundaries at $X_{\mathrm{a}, \mathrm{W}}=0$ and $X_{\mathrm{a}, \mathrm{E}}=20480 \mathrm{~km}$ (a bit less than the length of the zonal circle at $45^{\circ} \mathrm{N}$ ) are open, and periodic conditions are assumed. The atmosphere overlies the ocean and land. The interior oceanic and atmospheric depths are $H_{\mathrm{o}}=4 \mathrm{~km}$ and $H_{\mathrm{a}}=10 \mathrm{~km}$. The mean depth of the lower oceanic layer is $D_{\mathrm{o}, 2}=3 \mathrm{~km}$. A rigid lid is assumed, so the mean thickness of the upper oceanic layer is $D_{\mathrm{o}, 1}=H_{\mathrm{o}}-D_{\mathrm{o}, 2}$. On the top of the ocean there is a mixed layer of the constant thickness $h_{\text {mix }}=30 \mathrm{~m}$. 


\section{$2.2 \quad$ Atmospheric component}

The atmospheric model is described in detail in Kravtsov et al. (2002). The equations for the barotropic component $\psi$ and baroclinic component $\tau$ of the streamfunction are

$$
\begin{aligned}
\frac{\partial q_{\psi}}{\partial t}+J\left(\psi, q_{\psi}\right)=-h_{1} \frac{1}{t_{\mathrm{d}}} \nabla^{2} \psi-\sum_{k=0}^{3} \frac{1}{t_{\mathrm{d}}^{k}} \nabla^{2} \psi^{k} & +A_{\mathrm{H}} \nabla^{6} \psi \\
& -h_{1} h_{2}\left[J\left(\tau, q_{\tau}\right)+\frac{1}{t_{\mathrm{d}}} \nabla^{2} \tau\right], \\
\frac{\partial q_{\tau}}{\partial t}+\left(h_{2}-h_{1}\right) J\left(\tau, q_{\tau}\right)=\frac{f_{0}}{H_{\mathrm{a}}} \frac{1}{h_{1} h_{2}} F(\tau, x, y, t) & -h_{2} \frac{1}{t_{\mathrm{d}}} \nabla^{2} \tau-\sum_{k=0}^{3} \frac{1}{t_{\mathrm{d}}^{k}} \nabla^{2} \tau^{k}+A_{\mathrm{H}} \nabla^{6} \tau \\
- & {\left[J\left(\tau, q_{\psi}\right)+J\left(\psi, q_{\tau}\right)+\frac{1}{t_{\mathrm{d}}} \nabla^{2} \psi\right] . }
\end{aligned}
$$

Here

$$
q_{\psi}=\nabla^{2} \psi+\beta y, \quad q_{\tau}=\nabla^{2} \tau-\frac{1}{R_{\mathrm{d}}^{2}} \tau
$$

are the barotropic and baroclinic component of the potential vorticity, respectively, and $\tau$ is related to the atmospheric temperature $T_{\mathrm{a}}$, to be defined below. $h_{1}=0.3$ and $h_{2}=0.7$ are nondimensional thicknesses of the lower and upper atmospheric layers, $R_{\mathrm{d}}=383 \mathrm{~km}$ is the Rossby radius of deformation, $f_{0}=10^{-4} \mathrm{~s}^{-1}$ is the Coriolis parameter, $\beta=1.87 \times 10^{-11} \mathrm{~m}^{-1} \mathrm{~s}^{-1}$ is the gradient of the Coriolis parameter at $45^{\circ} \mathrm{N}, t_{\mathrm{d}}=4.62$ day is the bottom drag time scale, and $A_{\mathrm{H}}=-2 \times 10^{16} \mathrm{~m}^{4} \mathrm{~s}^{-1}$ is the damping coefficient. In our model, damping acts on both the barotropic and baroclinic component of the motion in the form of superviscosity. The atmospheric forcing function $F$ is described in the next subsection and has dimensions of velocity, and $J(A, B) \equiv \frac{\partial A}{\partial x} \frac{\partial B}{\partial y}-\frac{\partial A}{\partial y} \frac{\partial B}{\partial x}$ is the Jacobian.

Additional damping terms with the characteristic time scales of $t_{\mathrm{d}}^{0}=17$ day, $t_{\mathrm{d}}^{1}=23$ day, $t_{\mathrm{d}}^{2}=29$ day and $t_{\mathrm{d}}^{3}=37 \mathrm{~d}$ are included, following Vautard et al. (1988). They act selectively on the first zonal planetary modes $(0,1,2,3)$ to prevent the excessive accumulation of energy in these modes that is inherent to rigid-lid channel models, due to the lack of meridional and vertical dispersion. These missing processes affect primarily the largest zonal atmospheric scales (Held 1983). The fields $\psi^{k}$ and $\tau^{k}, 1 \leq k \leq 3$, are obtained by Fourier transforming $\psi$ and $\tau$ in $x$ and then truncating their inverse transform to retain only the $k$-th spectral component. 


\subsection{Radiation and heat exchange}

The coupled model is forced by temporally constant, latitudinally varying insolation, so the model climatology is not specified in advance. Over land, the insulating condition is imposed. The net (incident less reflected) shortwave radiation at the top of the atmosphere $R$, expressed in $\mathrm{W} \mathrm{m}^{-2}$, is

$$
R=182.04-162.92 \sin \left(2 y / a_{\mathrm{E}}\right)
$$

where $a_{\mathrm{E}}=6400 \mathrm{~km}$ is the radius of the Earth. The above formula is a reasonable fit to observations (e.g., Stephens et al. 1981). We parameterize other heat fluxes through the SST $T_{\mathrm{s}}$, and the atmospheric temperature $T_{\mathrm{a}}$ to be defined below. Our atmosphere is transparent to shortwave radiation, while it radiates in the longwave range both upward and downward with intensity $B$ and exchanges heat fluxes with the ocean: $O$ is the outgoing longwave oceanic radiation and $H_{\mathrm{SL}}$ is the sensible and latent heat exchanged between the ocean and the atmosphere.

Thus, over the ocean, the atmospheric forcing function is

$$
F=\frac{1}{\rho_{\mathrm{a}} c_{\mathrm{P}} \Delta \theta_{\mathrm{s}}}\left(O+H_{\mathrm{SL}}-2 B\right)
$$

where $\Delta \theta_{\mathrm{s}}=50 \mathrm{~K}$ is the difference in potential temperature between the layers, $\rho_{\mathrm{a}}=1 \mathrm{~kg} \mathrm{~m}^{-3}$ is the representative atmospheric density, and $c_{\mathrm{P}}=1000 \mathrm{~J} \mathrm{~kg}^{-1} \mathrm{~K}^{-1}$ is the atmospheric heat capacity. Neglecting the heat capacity and conductivity of the land surface results in the forcing function

$$
F=\frac{1}{\rho_{\mathrm{a}} c_{\mathrm{P}} \Delta \theta_{\mathrm{s}}}(R-B),
$$

valid over land.

The atmospheric back radiation $B$ (Budyko 1969) is parameterized as

$$
B=B_{0}+B_{\mathrm{t}} T_{\mathrm{a}}
$$

where the values of $B_{0}=213 \mathrm{~W} \mathrm{~m}^{-2}$ and $B_{\mathrm{t}}=1.63 \mathrm{~W} \mathrm{~m}^{-2} \mathrm{C}^{-1}$ are taken from Wang and Stone (1980) and $T_{\mathrm{a}}$ is measured in degrees C. We define an atmospheric equilibrium temperature as the mean temperature of the atmosphere in the absence of the heat exchange with the ocean:

$$
T_{\mathrm{eq}}=\frac{1}{B_{\mathrm{t}} \Sigma_{\mathrm{a}}} \iint_{\Sigma_{\mathrm{a}}}\left(R-B_{0}\right) d x d y
$$


The atmospheric temperature $T_{\mathrm{a}}$ is then found as the average temperature of an air column in a given location

$$
T_{\mathrm{a}}=T_{\mathrm{eq}}-\frac{f_{0} \tau}{g^{\prime} H_{\mathrm{a}}} \Delta \theta_{\mathrm{s}}
$$

Reduced gravity is assigned the value $g^{\prime} \equiv \frac{g H_{\mathrm{a}}}{\theta_{\mathrm{s}}} \frac{d \theta_{\mathrm{s}}}{d z} \sim 0.7$, where $g=9.82 \mathrm{~m} \mathrm{~s}^{-2}, z$ is a vertical coordinate and $\theta_{\mathrm{s}}=\theta_{\mathrm{s}}(z)$ stands for the potential temperature profile at static equilibrium.

The outgoing oceanic longwave radiation absorbed by the atmosphere is

$$
O=\sigma_{\mathrm{B}} T_{\mathrm{r}}^{4}+4 \sigma_{\mathrm{B}} T_{\mathrm{r}}^{3} T_{\mathrm{s}}
$$

here $T_{\mathrm{r}}=273 \mathrm{~K}$ is a reference temperature, $\sigma_{\mathrm{B}}=5.7 \times 10^{-8} \mathrm{~W} \mathrm{~K}^{-4}$ is the Boltzmann constant, and $T_{\mathrm{s}}$ is measured in degrees $\mathrm{C}$. The heat exchange between the ocean and the atmosphere is parameterized in a standard fashion (Haney 1971) as

$$
H_{\mathrm{SL}}=\lambda\left(T_{\mathrm{s}}-T_{\mathrm{a}}\right)
$$

with $\lambda=30 \mathrm{~W} \mathrm{~m}^{-2} \mathrm{C}^{-1}$.

\subsection{Ocean model}

The ocean model is standard and subjected to no-slip boundary conditions. We choose a horizontal viscosity of $A=300 \mathrm{~m}^{2} \mathrm{~s}^{-1}$ and oceanic Rossby radius of deformation of about $45 \mathrm{~km}$. With these, the ocean model is put into a moderately turbulent regime of Berloff and McWilliams (1999).

The ocean-atmosphere coupling occurs through the mixed layer, where the geostrophic and Ekman currents, as well as local air-sea heat exchange can affect SST. The latter, in turn, influences the atmosphere. Assuming perfect mixing of the heat and momentum and neglecting (small) mass transports due to the horizontal density gradients in the mixed layer, we obtain the following expressions for the $x$ - and $y$-velocity components $u_{\mathrm{o}}$ and $v_{\mathrm{o}}$ :

$$
\begin{gathered}
u_{\mathrm{o}}=-\frac{1}{f_{0}} \frac{\partial p_{1}}{\partial y}+\frac{\tau^{\mathrm{y}}}{f_{0} h_{\mathrm{mix}}}, \\
v_{\mathrm{o}}=\frac{1}{f_{0}} \frac{\partial p_{1}}{\partial x}-\frac{\tau^{\mathrm{x}}}{f_{0} h_{\mathrm{mix}}} .
\end{gathered}
$$


The velocity in the mixed layer is the sum of the two parts, namely, the geostrophic component expressed through the upper oceanic interior layer streamfunction $p_{1}$, and the Ekman component due to the direct action of the atmospheric wind stress $\left(\tau^{\mathrm{x}}, \tau^{\mathrm{y}}\right)$ on the mixed layer. In consistency with our atmospheric model, the wind stress is a linear function of the atmospheric wind

$$
\tau^{\mathrm{x}}=c_{\mathrm{D}} u_{1}, \quad \tau^{\mathrm{y}}=c_{\mathrm{D}} v_{1},
$$

where $c_{\mathrm{D}}=2 \times 10^{-5} \mathrm{~m} \mathrm{~s}^{-1}$.

The SST dynamics is governed by

$$
\frac{\partial T_{\mathrm{s}}}{\partial t}+\frac{\partial}{\partial x}\left(u_{\mathrm{o}} T_{\mathrm{s}}\right)+\frac{\partial}{\partial y}\left(v_{\mathrm{o}} T_{\mathrm{s}}\right)=\frac{w_{\mathrm{E}}}{h_{\text {mix }}}\left\{\begin{array}{c}
T_{1}: w_{\mathrm{E}} \geq 0 \\
T_{\mathrm{s}}: w_{\mathrm{E}}<0
\end{array}+\frac{F_{\mathrm{a}-\mathrm{o}}}{\rho_{\mathrm{o}} c_{\mathrm{P}, \mathrm{o}} h_{\mathrm{mix}}}+\kappa \nabla^{2} T_{\mathrm{s}},\right.
$$

where $\rho_{\mathrm{o}}=1000 \mathrm{~kg} \mathrm{~m}^{-3}$ is the representative oceanic density, $F_{\mathrm{a}-\mathrm{o}}$ is the vertical heat flux experienced by the ocean surface, $c_{\mathrm{P}, \mathrm{o}}=4000 \mathrm{~J} \mathrm{~kg}^{-1} \mathrm{~K}^{-1}$ is the oceanic heat capacity, $T_{1}=10^{\circ} \mathrm{C}$ is the temperature of the upper oceanic interior layer, $\kappa=300 \mathrm{~m}^{2} \mathrm{~s}^{-1}$ is the mixed-layer thermal diffusivity and the Ekman pumping is

$$
w_{\mathrm{E}}=h_{\text {mix }}\left(\frac{\partial u_{\mathrm{o}}}{\partial x}+\frac{\partial v_{\mathrm{o}}}{\partial y}\right)
$$

If $w_{\mathrm{E}}<0$ (downward), the ocean interior experiences the heat flux

$$
F_{\mathrm{o}}=-\rho_{\mathrm{o}} c_{\mathrm{P}, \mathrm{o}} w_{\mathrm{E}}\left(T_{\mathrm{s}}-T_{1}\right)
$$

In solving Eq. (12), the insulating condition is imposed on the boundaries.

In our model, a single temperature represents the entire atmospheric column, and enters the bulk-formula parameterization of the air-sea heat exchange (9). Therefore, SST affects the interior atmospheric circulation directly, so that the sensitivity of the model atmosphere to surface boundary condition may be overestimated relative to that in a model with higher vertical resolution. However, this does not necessarily imply that the coupled effects will be exaggerated. The possibility of a coupled low-frequency variability in such a system is not a trivial matter. Marotzke and Pierce (1997) studied the evolution of an SST anomaly in a simple 50-m-thick slab mixed-layer model coupled to a one-dimensional diffusive atmosphere through the relaxation law with the coupling coefficient $\lambda=50 \mathrm{~W} \mathrm{~m}^{-2} \mathrm{~K}^{-1}$, so that the tendency in the 
SST equation due to air-sea heat exchange (proportional to $\lambda / h_{\text {mix }}=1$ ) is the same as in our model. They provided an elegant demonstration of the dependence of the model response on the spatial scale of the SST anomaly and identified various relevant time scales, corresponding to different stages of SST evolution. Here, we will explore the potential for oceanically induced SST anomalies to affect the atmospheric circulation and be reinforced by the latter on the slow time scales associated with the ocean currents.

\section{Uncoupled results}

\subsection{Atmospheric climate and variability}

A summary of experiments is given in Table 1. We first specify the SST distribution as

$$
T_{\mathrm{s}}=12.4+17.0 \sin \left(2 y / a_{\mathrm{E}}\right)
$$

and perform a 75-year-long atmospheric integration (experiment A1 of Table 1). Eq. fits well the observed annual mean temperature profile (e.g., North et al. 1981). Displayed in Fig. 2 is the time averaged distribution of the zonally averaged zonal velocity in each of the atmospheric layers. It shows a well-centered midlatitude westerly atmospheric jet in both layers with a reasonable meridional structure. The amplitude of the upper layer jet is slightly weaker than observed and the lower layer winds at the sides of the atmospheric channel are distorted due to deficiencies of the quasi-geostrophic formulation.

\subsubsection{Time averaged fields}

Spatial distributions of the time averaged atmospheric fields are shown in Fig. 3. In panel (a), isotachs of the zonal barotropic component of the wind are plotted, along with the turbulent barotropic kinetic energy (shading). Panel (b) shows the distributions of the atmospheric temperature and its variance (shading). Maximum zonal winds occur over land with the jet break situated above the ocean in the model (consistent with the thermal wind balance), while the observed Atlantic jet extends further into the ocean. In the oceanic region, the model's atmospheric temperature and SST are tied together by a strong relaxation law, representing the ocean-atmosphere heat flux. This flux directly affects the baroclinic structure of the model 
atmosphere. In the land region, where an insulation condition is imposed, the north-to-south temperature contrast is affected directly by the solar forcing and the resulting temperature gradient is steeper. There is no pronounced stationary wave in the model atmosphere due, most likely, to the absence of mountains in the model.

\subsubsection{Variance}

The model produces a clear storm track. The temperature variance (constructed using unfiltered daily data) has a maximum slightly downstream of the maximum winds location (Fig. 3b), and can be shown to be dominated by the high-frequency baroclinic disturbances. The barotropic-wind variance (Fig. 3a), which is dominated by the lower frequencies, is maximum even further downstream, closer to the exit of the jet and slightly to the north of the jet axis. Although the position of the mean jet relative to the ocean differs from observations, the relative locations of the jet break, storm track and maximum low-frequency barotropic activity are well reproduced. The amplitudes of the variances also agree with observations. The atmospheric temperature variability over the ocean (Fig. 3b) is weak partly because of the direct effect of the air-sea heat exchange mentioned above, and partly because the weaker atmospheric jet over the ocean is more baroclinically stable. However, this should not seriously impact the coupled behavior because the ocean tends to be insensitive to the high-frequency content of the atmospheric variability. In contrast, there is vigorous barotropic-wind variability over the ocean (Fig. 3a). Oceanic variability and ocean-atmosphere coupled behavior are likely to be associated primarily with, and sensitive to, the time-dependent structure of the barotropic wind, since it is here that the atmospheric low frequences almost entirely reside.

\subsubsection{EOFs}

To analyze the spatial structure of the atmospheric variability further, we perform a standard principal component (PC) analyses of the atmospheric fields (unfiltered daily data). In Fig. 4, we plot the first empirical orthogonal function (EOF) of the barotropic streamfunction, accounting for approximately $35 \%$ of the total variance. The zonally averaged structure of this EOF corresponds to the meridional shifts of the jet and is qualitatively similar to that obtained by Koo (2001) in an atmospheric model without asymmetries at the lower boundary. This EOF 
can be compared to the midlatitude part of the Arctic Oscillation (AO). There is, however, no opposite-polarity center in the north, most likely due to the channel geometry of the model.

This EOF also exhibits a nontrivial zonal modulation over the midlatitude ocean that is capable of introducing a spatially coherent forcing on the ocean circulation through Ekman pumping. Although the zonal asymmetry in the model's leading mode of atmospheric variability over the ocean is smaller than observed, there is nonetheless a qualitative similarity with the North Atlantic, where the southern pole of the wintertime AO straddles the mean surface zonal-wind maximum. It is worth noting that even full atmospheric GCMs exaggerate the zonal symmetry of the AO (e.g,. Robertson 2001)

The corresponding PC has a red spectrum without any localized peaks (Fig. 5a). This power spectrum was computed by dividing the time series into overlapping 5500-day segments and averaging over the 10 periodograms so obtained. In Fig. 5b, we plot in more detail the lowfrequency portion of the spectrum. In this case, 200-day means of the PC time series were used to construct a multi-taper spectrum with 5 tapers (Dettinger et al. 1995), describing the lowfrequencies in more detail. The spectrum is very weakly red. Also plotted in Fig. 5b are 90\% and $95 \%$ confidence intervals (Mann and Lees 1996). There is no known physical mechanism able to support such an ultra-low-frequency oscillatory behavior in the atmosphere, so the seemingly significant peaks seen in the spectrum are most likely due to sampling variations.

\subsection{Oceanic climate and variability}

\subsubsection{Climatology and time-dependent behavior}

We next perform two uncoupled 375-year-long oceanic experiments and analyze the last 300 years of these integrations. The first run (hereafter the steadily-forced run; O1a of Table 1) is

forced by the climatological values taken from the atmosphere-only integration. The second oceanic integration (the stochastically-forced; O1b of Table 1) uses the daily-archived output from the atmospheric run. The atmospheric run is only 75-years-long, so we use the atmospheric data repeatedly 5 times.

The climatology is very similar in both ocean-only runs, and is shown for the stochastically forced run in Fig. 6. The barotropic transport is plotted in panel (a), oceanic interface height 
relative to the boundary in panel (b) and SST distribution in panel (c). Note that by our definition (see Fig. 1), a negative interface height corresponds to a deeper "thermocline." Thus, in Fig. 6 there is a clockwise circulation around the subtropical gyre and an anticlockwise one around the subpolar gyre, both of which are largest in the upper layer. Due to the use of the no-slip boundary condition, the climatology is characterized by the presence of a double jet near the western oceanic boundary (cf. Haidvogel et al. 1992), which corresponds to the Gulf Stream and Labrador Current. In reality, the two currents exist as separate entities at distances from the western boundary up to half the basin size, where they eventually merge. The maximum value of the barotropic transport found in the subtropical gyre recirculation region is about $60 \mathrm{~Sv}$. The structure of the baroclinic circulation shown in panel (b), and of the SST field (panel (c)), are also reasonable (cf. Cessi 2000). In the deep ocean, the baroclinic and barotropic components of the flow tend to compensate each other, leading to the surface-intensified currents.

Although the climatologies of the two runs are similar, the variability is dramatically different. In the steadily forced integration, the variability in the model has a spectrum dominated by low-frequency baroclinic motions with most intensity in the region of the western boundary currents separation. These motions have a scale of the oceanic internal Rossby deformation radius and form vortex-like structures similar to those found in many other quasi-geostrophic models (e.g., Berloff and McWilliams 1999). An EOF analysis (not shown) indicates that the variabilities of the two jets are independent (or decoupled) of each other. The EOFs of the oceanic fields for the stochastically forced integration are plotted in Fig. 7, using both unfiltered (upper panels) and 5-year-low-pass filtered (lower panels) oceanic data. The filter (Otnes and Enochson 1978) is applied to 200-day means of the data time series. Only the data from a small rectangle in Fig. 6 has been used for the EOF analysis, corresponding to the region of most intense oceanic variability.

In all cases the leading EOF is well separated from the second EOF, and accounts for a significant portion of the oceanic variability (see caption of Fig. 7). The first EOF of the unfiltered barotropic transport (Fig. 7a) shows a pattern similar to that of the first EOF of the atmospheric barotropic streamfunction (Fig. 4). It is clearly directly forced by the atmospheric wind, and we verify this below. An interesting feature of the oceanic baroclinic 
pressure variability (Fig. 7b) is a synchronous and large-scale (larger than the oceanic internal Rossby radius) variability in the double-jet region. This synchronization occurs through the atmosphere and is absent in the steadily forced run. The combined effect of the baroclinic and barotropic modes produces a large amplitude $\left(\sim 1.5{ }^{\circ} \mathrm{C}\right)$ large-scale $(\sim 1000 \mathrm{~km})$ meridionally aligned SST dipole (Fig. 7c).

The lower panels of Fig. 7 show that on interannual-to-interdecadal time scales, the oceanic regional variability is dominated by the baroclinic component of the circulation. The similarity between Fig. 7 (b) and (e) confirms that the baroclinic response of the ocean is dominated by the low frequencies. The baroclinic motions influence the barotropic field through nonlinear interaction (cf. Fig. 7 (d) and (e)) and advect SST (Fig. 7f). The EOF of low-pass filtered SST still retains a large-scale dipolar component evident in Fig. 7c, albeit with a smaller amplitude and smaller-scale spatial modulation. It may still be potentially important in inducing an atmospheric response on very long time scales.

\subsubsection{Connection with the atmospheric variability}

Figure 8 shows the 5-year-low-pass filtered normalized $\mathrm{PC}_{1}$ of the oceanic interface displacement (corresponding to the EOF in Fig. 7e), lagged by 2.75 years, together with the normalized $\mathrm{PC}_{1}$ of the atmospheric barotropic wind (corresponding to the EOF in Fig. 4). This lag produces a maximum correlation of 0.7 between the two time series, demonstrating that the leading component of oceanic variability follows the low-frequency component of the atmospheric history; it involves no dynamically active internal oceanic mode excited by the atmospheric noise. The time lag required for maximum correlation may be understood by computing the time necessary for the long oceanic baroclinic Rossby waves to travel across the scale of the atmospheric forcing $(\Delta L \sim 2000 \mathrm{~km})$ to the western boundary of the ocean, where most of the variability occurs. This calculation gives

$$
\Delta L \beta^{-1} R_{\mathrm{d}}^{-2} \sim 2.23 \quad \text { year }
$$

which is close to the time lag value above. We cannot conclude definitively, however, that oceanic Rossby-wave propagation determines the time lag between the atmospheric forcing and the oceanic response. Dewar (2001) argues that nonlinear adjustment of oceanic inertial recirculation might be more important. In addition, mean-circulation advective time scales are 
also on the order of several years.

\subsubsection{Basin-scale oceanic variability}

The simple ocean models reviewed in the introduction often exhibit basin-scale behavior (e.g., Jin 1997; Cessi 2000). Figure 9 shows the leading EOFs using the data from the whole oceanic basin on a coarser $160 \times 160$-km grid.

The structures of the basin-scale EOFs are consistent those of the regional analysis in Fig. 7 , indicating that the latter structures near the western boundary form an important part of the leading basin-scale variability. None of the corresponding spectra (not shown) exhibits any significant spectral peaks and, as in the regional case, the basin-scale oceanic variability can be clearly interpreted as a direct response to the atmospheric forcing, conducted to the regions of strong currents by, arguably, the large-scale baroclinic Rossby waves.

\section{Coupled results}

\subsection{Atmospheric climate and variability}

We now couple the oceanic and atmospheric models and perform a 500-year-long integration of the full model, analyzing the last 350 years of this integration (experiment CO of Table 1). The model components were spun up using the uncoupled runs. The coupled model is in statistical equilibrium, i.e., there is no long-term drift of the model variables during the last 350 yr of the integration.

The climatological structure of the atmosphere arising in the coupled integration is shown in Fig. 10. It should be compared to that from the uncoupled integration (Fig. 3). The jet in the coupled run is slightly weaker and displaced slightly equatorward (panel (a)), consistent with angular momentum conservation. An increase in temperature variance is clearly seen from comparison of Figs. 10b and 3b. The total barotropic turbulent kinetic energy in the coupled run is also increased (cf. Figs. 3a and 10a). Despite these quantitative changes, the spatial structure of the atmospheric mean values and variances remains similar.

The changes in the strength of the atmospheric variability between the coupled and uncoupled runs can be explained as the result of differences in the climatological SST field and 
corresponding adjustments in the strength of the atmospheric flow. To confirm this, we have performed an additional 75-year-long atmosphere-only integration forced by the SST climatology from the coupled run (experiment A2 of Table 1). The spatial pattern and strength of the climatological and time-dependent atmospheric circulation in this run are virtually indistinguishable from those in the coupled run (but see below).

The first EOF of the barotropic streamfunction (Fig. 11) is similar in structure to that in the uncoupled case. An examination of the atmospheric spectra corresponding to the leading EOF of the barotropic wind (Fig. 12) shows that there is no additional regularity introduced into the atmospheric behavior through coupling on interdecadal time scales. The spectra in Fig. 12 were constructed analogously to those in Fig. 5 and are very similar to those of the uncoupled run. Not more than $5 \%$ of frequencies pass the $95 \%$ confidence level in Fig. 12b, indicating that the spectral peaks seen there can be attributed to sampling variations. The relative power contained in the high- and low-frequency portions of both coupled (Fig. 12) and uncoupled (Fig. 5) spectra is roughly the same (cf. Robertson 2001), providing further evidence that the coupling is negligible and that the dominance of the low frequencies in the model atmosphere is due to intrinsic atmospheric nonlinearities (cf. James and James 1989).

A more careful analyses can be performed by comparing the coupled spectrum with the spectrum (not shown) of the corresponding PC from the atmosphere-only run forced by the climatological SST from the coupled run (A2 of Table 1, see above). It is then possible to identify a very weak, but distinguishable increase in the power contained in the low-frequency portion of the coupled model spectrum.

\subsection{Oceanic climate and variability}

\subsubsection{Climatology and time-dependent behavior}

Changes in climatology The oceanic climatology resulting from the coupled integration is displayed in Fig. 13. It should be compared with analogous uncoupled results (Fig. 6). The qualitative nature of the circulation and SST pattern are similar in the two runs. However, there is an important southward displacement of the gyres in the coupled relative to the uncoupled case, of about $500 \mathrm{~km}$. In addition, the spatial scale of the recirculation zone (panel (a)) is 
dramatically increased in the coupled run, especially in the subtropical-gyre region. There is an additional tropical gyre (Fig. 13 a, b) and the mean north-south SST gradient is increased in accordance with a similar increase in the atmospheric temperature gradient (cf. Figs. 3b and 10b). An additional uncoupled oceanic integration forced by the atmospheric history from the coupled run (O2b of Table 1) reproduces all these changes, showing that they are entirely due to an adjustment of the oceanic and atmospheric circulations that arise during the first decade after coupling.

Regional response We perform a regional EOF analysis of the oceanic fields in the small rectangle in Fig. 13 and compare it with analogous analysis of the uncoupled fields (Figs. 7 and 8). We find that in this regional sense, the coupled system behaves very similarly to the uncoupled one (not shown). That is, the low-frequency response in the region of the boundary currents confluence zone and inertial recirculations is predominantly baroclinic and represents a passive synchronous adjustment of the two jets to the atmospheric anomalies, generated to the east of the western oceanic boundary and possibly carried to this boundary by large-scale baroclinic Rossby waves. Since the location of the atmospheric anomaly is the same in the coupled and uncoupled runs, the time lag of the oceanic response should be the same as well, and it is indeed found again to be 2.75 years.

Oceanic intrinsic mode Interesting differences arise in the analysis of the basin-scale oceanic EOFs. The first EOF of the interface displacement (Fig. 14a, cf. Fig. 9b) possesses a broad spectral peak around 5.5 years (Fig. 14b), with no counterpart in the uncoupled integrations discussed in Section 3. However, this mode is reproduced in an additional oceanonly integration using the atmospheric history from the coupled run as a forcing (O2b of Table 1), while it is absent from the ocean-only integration forced by the atmospheric climatology from the coupled run (O2a of Table 1). It thus appears to be a damped intrinsic mode of the oceanic circulation that is excited by the atmospheric stochastic forcing. Note that the period of the oscillation is twice the time lag, mentioned in previous paragraph.

The ability of the atmospheric noise to excite this mode appears to depend on the relative locations of the oceanic time-mean circulation and atmospheric stochastic forcing, since this differs significantly between the control (forced by the atmospheric history from the idealized 
atmosphere-only integration; O1b of Table 1) and the additional (forced by the atmospheric history from the coupled run; O2b of Table 1) ocean-only integrations. The meridional displacement of the jets does not affect the eigenmodes due to $\beta$-plane QG approximation, where all latitudes away from the boundaries are dynamically equivalent.

There is no apparent signature of this mode in the barotropic transport and SST fields. Thus, the heat flux due to advection of the mean SST by a baroclinic field anomaly is weak compared to other components of the total heat flux. This is due to the spatial structure of the mode, whose currents are directed almost perpendicular to SST gradients, at least in the locations where the latter are strong. Since the only way for the ocean to affect the atmosphere is through SST, the internal oceanic mode does not influence the atmosphere, which is consistent with the red-noise structure of the atmospheric variability.

Basin-scale response of SST to atmospheric forcing None of the other oceanic basinscale EOFs exhibit any significant peaks in the spectra of the corresponding PCs. In Fig. 15, we plot the first EOF of the barotropic transport, the second EOF of the interface displacement and the first EOF of SST, using 200-day means (upper panels), as well as the leading EOFs of the 5year-low-pass filtered data (lower panels). The first EOF of SST (Fig. 15c,f) has a structure that is qualitatively similar to that observed by Kushnir (1994): positive temperature anomalies of realistic amplitude occur over most of the northern model ocean, with two centers of action near the western boundary. They are separated by a negative anomaly, whose boundary coincides with the location of the two climatological jets, which are considered to be the model "Gulf Stream" and "Labrador" currents. Two other centers are located toward the eastern boundary, where a positive anomaly is seen in the north and a negative anomaly in the south. However, the amplitude of the negative anomaly is much larger than that of the weak observed anomaly in the tropics, due, probably, to an oversimplified mixed-layer model.

The SST pattern in Fig. 15c is concurrent with a negative atmospheric pressure anomaly over the ocean (Fig. 11), in a similar manner to that found in interdecadal observations (Kushnir 1994). The time series of the leading PCs of the atmospheric streamfunction and SST are highly correlated (correlation of 0.7) at zero lag (recall that the sampling interval we use is 200 days). Correlating the PCs of the other oceanic fields and atmospheric pressure anomalies shows that 
the patterns plotted in Figs. 15a,b,c occur approximately simultaneously (correlation of 0.5). The temporal correlations between the time series of the oceanic and atmospheric fields are even higher (correlation of 0.7 ) if we use the 5-year-low-pass filtered data. The same behavior is obtained in the ocean-only integration using the atmospheric history from the coupled run as a forcing (O2b of Table 1). All of this argues that the spatial structures obtained represent a passive response of the ocean to the low-frequency evolution of the atmospheric flow. A negative atmospheric pressure anomaly accompanies a warm basin-scale SST pattern (Fig. 15c), intensified model "Gulf Stream" and reduced intensity of the model "Labrador current" (Fig. 15a,b). These features have also been alluded to in observations of interdecadal variability in the North Atlantic (Levitus 1989a,b; Greatbatch et al. 1991).

\subsubsection{Mixed-layer dynamics}

We next investigate the evolution of the SST pattern in Figs. 15c,f and show that the dynamics differ across the basin. To do this, we compute the SST $(T)$ anomaly evolution associated with the EOFs of atmospheric and oceanic circulation (Figs. 11 and 15d,e), together with their corresponding PC time dependences. The mixed-layer equation (12) is finite differenced on a coarse $160 \times 160-\mathrm{km}$ grid and integrated forward in time for 350 years, with geostrophic $\left(u_{\mathrm{g}}, v_{\mathrm{g}}\right)$ components of mixed-layer velocities, as well as the atmospheric temperature $T_{\mathrm{a}}$, prescribed as time-dependent fields, and time-mean SST $(\bar{T})$ prescribed according to the full model solution. Dynamically important terms in this equation are shown to be the following:

$$
\frac{\partial T}{\partial t}=-u_{\mathrm{g}}^{\prime} \frac{\partial \bar{T}}{\partial x}-v_{\mathrm{g}}^{\prime} \frac{\partial \bar{T}}{\partial y}+\frac{\lambda}{\rho_{\mathrm{o}} c_{\mathrm{P}, \mathrm{o}} h_{\mathrm{mix}}} T_{\mathrm{a}}^{\prime}+E^{\prime}+\ldots
$$

where an overbar denotes a time mean, $u_{\mathrm{g}}^{\prime}, v_{\mathrm{g}}^{\prime}$ are the geostrophic velocity anomalies in the upper oceanic layer, $T_{\mathrm{a}}^{\prime}$ is the atmospheric temperature anomaly associated with the circulation pattern in Fig. 11, and $E^{\prime}$ term is explained below. Recall that there is no dependence of the surface heat flux on wind speed in the coupled model. In the geostrophic field, we will also distinguish between barotropic and baroclinic components of the flow. The entrainment heat flux parameterization in our mixed-layer model is highly nonlinear (see Eq. (12)). Thus we combine Ekman advection and entrainment heat fluxes in $E^{\prime}$. To determine $E^{\prime}$, we take the

time series of the wind anomaly (Fig. 11), the time series of the modeled SST anomaly (Fig. 
15f), mean wind and mean SST, and compute the time-mean entrainment heat flux as in (12). In the integration of (15), we first compute an entrainment heat flux using the same data with an exception of SST, which is now computed explicitly $(T) . E^{\prime}$ is then found as the difference between this instantaneous value and previously determined time mean.

The results of this integration are summarized in Fig. 16. In panel (a), we plot the first EOF of SST from the mixed layer run with all the terms included. The pattern obtained is reasonably close to that in Fig. 15c away from the zonal boundaries. The differences arise due to the fact that the time-dependent fields used to force the mixed-layer model are not perfectly correlated. The amplitude of the anomaly is slightly weaker than that from the coupled-model integration (note different contour interval), which can be due to the coarse spatial and temporal resolution in the mixed-layer model used here. Our mixed-layer model is potentially more justifiable in the midlatitude region, than in the tropical or polar regions, where significant changes in the mixed-layer depth and convective activity occur.

Figure $16 \mathrm{~b}$ shows the result of neglecting $T_{\mathrm{a}}$ variability. There are some quantitative differences throughout the basin, but the general structure survives. The heat flux associated with the atmospheric temperature anomaly generally tends to damp the SST anomaly, rather than to reinforce it.

However, dramatic changes occur over the ocean interior when we remove the effects of the anomalous Ekman and entrainment heat fluxes. In Fig. 16c, the only term retained in (15) is the advection of the mean temperature by the anomalous baroclinic current. Comparing panels (c) and (a) shows that near the western boundary, the anomalous SST structure is primarily determined by that heat transport. The barotropic contribution (panel $(\mathrm{d}))$ has a similar structure, but a somewhat smaller amplitude.

\section{Summary and Discussion}

We have studied the behavior of an idealized eddy-resolving quasi-geostrophic coupled oceanatmosphere model, meant as a minimal representation of the midlatitude climate over the North Atlantic. The coupling between the two-layer oceanic and atmospheric dynamical components occurs through a simple mixed-layer parameterization, where a diagnostic momentum closure allows us to compute the currents advecting SST; the latter influences the atmospheric 
circulations through the associated air-sea heat fluxes.

The atmospheric climatology consists of a zonally modulated climatological jet that has a reasonable intensity. The relative locations of the jet break, storm track and maximum lowfrequency barotropic activity are consistent with theoretical and observational expectations. The time-mean oceanic circulation consists of subtropical and subpolar gyres with a double midlatitude jet structure that bears similarities to the Gulf Stream-Labrador Current system. The Gulf Stream is known to separate from the coast at Cape Hatteras and to flow eastward a considerable distance before merging with the cold Labrador Current.

The coupled model reproduces some of the essential features of observed interdecadal variability over the North Atlantic. In the simulations, low atmospheric pressure anomalies (cf. Fig. 11) are accompanied by positive SST anomalies (Fig. 15f) over most of the midlatitude and northern part of the ocean basin (cf. Kushnir 1994), and by an intensified model Gulf Stream and weakened Labrador currents (Fig. 15d,e) (cf. Greatbatch et al. 1991). The model's SST anomalies also bear similarities with the pattern of interior oceanic temperature decadal change observed by Levitus (1989a,b). Negative SST anomalies occur between the Gulf Stream and Labrador currents, as well as at low latitudes (cf. Kushnir 1994).

We find, however, that the atmospheric behavior on time scales longer than interannual depends little on oceanic dynamics. The slight redness of the power spectrum of the barotropic atmospheric field (Fig. 12) is attributed to internal atmospheric nonlinearities (cf. James and James 1989), since there is virtually no change in the relative amplitude of the low- and highfrequency motions in the coupled and uncoupled atmospheric integrations. On the other hand, the oceanic low-frequency variability and SST anomalies are found to be primarily determined by the structure and time-dependence of the intrinsic atmospheric variability (Fig. 8).

Near the western boundary, the ocean-only integrations forced by the atmospheric climatology (O1a, O2a of Table 1) show that the variability in each of the two jets is independent of the other jet; it is dominated by baroclinic instability of the mean jet with spatial scales close to the ocean's Rossby deformation radius. This variability has a red spectrum due to nonlinearities in the ocean dynamics. The situation is very different in the integration forced by the atmospheric history from the coupled run (O2b of Table 1). Here, the dominant mode of oceanic regional variability is a delayed (by 2.75 years) synchronous response of the two jets to 
the atmospheric evolution. It has a larger spatial scale compared to the steadily forced case and its time dependence is fully determined by the temporal evolution of the atmospheric variables (Fig. 8). There is a dramatic increase in the size of the oceanic recirculation zones, which can be attributed to the action of the atmospheric noise. Thus, on both regional and basin scales, the atmospheric intrinsic variability in the model is shown to determine the ocean's leading low-frequency behavior.

The zonal location of the atmospheric variability may also affect the temporal characteristics of the model's variability due to a different delay time associated with the zonal shift of the atmospheric forcing. However, the passive oceanic response on time scales longer than the baroclinic adjustment time scale (manifested as our basin-scale SST mode) would not be altered.

Detailed analyses of the mixed layer dynamics (Fig. 16) demonstrate that in the region of the confluent mean western boundary currents, where strong meridional SST gradients occur, the SST response is largely due to the advection of mean SST by anomalous baroclinic currents associated with the wind anomaly. Over the rest of the basin, heat fluxes associated with the anomalous Ekman currents and entrainment in the mixed layer dominate. Thus, anomalously low SLP is associated with anomalous easterly surface winds north of $45 \mathrm{~N}$ leading to northward Ekman advection and warming. The effects of anomalous air-sea fluxes are relatively small, although their effect is underestimated by the model due to the absence of a dependence on the wind speed in Eq. (9).

Our model results suggest that observed interdecadal variability in the North Atlantic (e.g., Kushnir 1994) is consistent with a passive response of the ocean to atmospheric intrinsic variability, with the local surface processes dominating to the east, and a delayed modulation of oceanic currents near the western boundary. Thus, our results provide further evidence that the ocean plays an important advective role in interdecadal SST variability in the region of the Gulf Stream and Labrador current (Bjerknes 1964, Kushnir 1994). Our overall interpretation is generally consistent with the recent coarse resolution GCM study by Saravanan et al. (2000).

The model captures the negative SST anomalies along the western boundary seen in Kushnir (1994) and also in the coupled GCM study of Delworth et al. (1993). In our model they are associated with southward advection of mean SST by the anomalous geostrophic currents between the double jets. They have a y-scale determined by the distance between the two 
jets and would not exist without them. However, if the separation of the Gulf Stream and Labrador Current is driven by the coastline in reality, the same physics are possible before the two currents merge.

We thus speculate, based on our model results, that observed interdecadal SST changes over the North Atlantic can be driven by very-low-frequency components of the atmosphere's intrinsic "noise." In the model, the latter do have a structure that resembles the NAO, within the confines of the channel geometry. Krahmann et al. (2001) have suggested a similar scenario from analyses of a forced OGCM.

A notable discrepancy with the observations documented by Kushnir (1994) occurs in the nature of the atmospheric low which accompanies the basin-scale warm SST anomaly. In the model, the atmospheric low is cold and equivalent barotropic, with the warm SST resulting from anomalous poleward Ekman advection. In the observations, Kushnir and Held (1996) show evidence that the SLP anomaly is warm and baroclinic. They suggest that the latter may be a linear response of the atmosphere to the SST anomaly. To understand better the nature of SST effects on the atmospheric circulation in our model, we have performed an additional 75-year-long atmosphere-only run, which is forced by the climatological SST from the coupled run plus the SST anomaly distribution shown in Fig. 15c (experiment A3 of Table 1). We find that the atmospheric response to an imposed SST anomaly is very weak in amplitude compared to intrinsic atmospheric ultra-low-frequency variability (not shown). Therefore, it is likely that irrespective of the nature of SST dynamics in our model, its effect on the atmospheric behavior will be negligible.

A more advanced atmospheric model is required to check whether our results are sensitive to vertical resolution, to the wind speed dependence in the air-sea heat flux parameterization, or to the more realistic climatology. The GCM results of Peng et al. $(1995,1997)$ indicate that the atmospheric response to midlatitude SST anomalies may be strongly dependent on the background flow.

While the model does not exhibit coupled modes of variability, ocean-atmosphere coupling is found to give rise to important changes in model climatology, highlighted by comparing the original ocean-only integration (Fig. 6; experiment O1b of Table 1) with the one forced by the atmospheric history from the coupled run (the adjusted run; experiment $\mathrm{O} 2 \mathrm{~b}$ of Table 1). In 
the latter, the gyres are located 5 degrees farther to the south, very similar to the fully coupled run (Fig. 13), consistent with changes in the distribution of the climatological Ekman pumping (not shown), while the meridional shift of the atmospheric variability center is negligible (cf. Figs. 4 and 11). Thus, the relative meridional locations of the ocean gyres and atmospheric variability are changed, which has important implications for the variability of SST and ocean circulation. In the coupled model, the leading EOF of SST (Fig. 15c) is more similar to Kushnir's (1994) observed pattern in the western basin, than is the uncoupled EOF (Fig. 9). The latitudes of maximum zonal wind anomalies are much closer to the double oceanic jets in the coupled run, tending to force changes in their intensities. The recirculation zone has a much larger spatial scale. In the first ocean-only run, the anomalous currents and mean SST are not spatially compatible, because the latter does not influence the climatology of the model atmosphere.

In addition to the passive oceanic response to the atmospheric forcing, we also find an intrinsic damped oscillatory oceanic mode in the baroclinic pressure field, that is excited by the atmospheric noise. It has a period of around 5.5 years, which is close to twice the characteristic time necessary for the large-scale internal oceanic Rossby waves to propagate from the region of maximal atmospheric low-frequency variability to the western boundary of the ocean. This mode is found to have a negligible influence on SST evolution due to orthogonality of the associated currents to mean SST gradients. It is not found in the original ocean-only integration, again highlighting the importance of coupling in setting the mean state.

Our high-horizontal-resolution ocean model does possess a rich spectrum of the intrinsic variability, associated with baroclinic eddies, but the atmospherically forced modes strongly dominate over this variability. This result suggests that coarse resolution ocean GCMs, not resolving oceanic eddies, may be sufficient for simulations of the midlatitude climate dynamics. On the other hand, our model may be overly viscous. Dewar (2001) has argued that oceanic nonlinear baroclinic activity may affect midlatitude SST variability, and observational support is found by Qiu (2000), so that experiments in a more turbulent oceanic regime should be pursued. Furthermore, the spatial structure of the leading pattern of SST variability in the vicinity of the western oceanic boundary is found to be due to the presence of the double midlatitude oceanic jet, which, in turn, requires the use of high horizontal resolution and no- 
slip boundary conditions (cf. Haidvogel et al. 1992). A double jet has not been reproduced in equivalent-barotropic models of the oceanic circulation (e.g., Jin 1997), suggesting that two layers, at least, are required in order to capture its essential dynamics.

Our model does not reproduce the vigorous ocean-only modes found by Speich et al. (1995) in an uncoupled equivalent-barotropic ocean model. This discrepancy may be due to differences in model formulation (quasi-geostrophic versus shallow-water, two-layer versus 1.5-layer, higher horizontal resolution, no-slip versus free-slip boundary conditions, higher Reynolds number). In midlatitudes, the isopycnal displacements are small so that the QG approximation is well founded and is likely to reproduce the shallow-water results. Our model is dynamically more complete than the reduced-gravity model, since it resolves baroclinic instability.

Our results also contrast with previous idealized studies of midlatitude ocean-atmosphere interaction (Liu 1993; Jin 1997; Weng and Neelin 1998; Münnich et al. 1998; Cessi 2000) that found coupled midlatitude dynamics to be important. However, all of these studies effectively specified an ocean-atmosphere feedback, together with white noise, while ours is a fully coupled model. The positive feedback in these models is associated with hypothesized intensification of the atmospheric jet in response to changing SST pattern. If, however, the atmospheric jet response is realized primarily through shifts in the jet position, as it is in our model, then the positive feedback may not occur.

Schneider et al. (2002) have analyzed the behavior of a coupled GCM in the Pacific and alluded to a mode of variability, dynamically similar to that in our model (see also Xie et al. 2000). Delworth et al. (1993) found an SST pattern that is similar to ours, in the global GCM study, which they associated with variability of the thermohaline circulation in the North Atlantic. Our results suggest that it might equally be due to wind induced processes in the upper ocean. Nonetheless, such anomalies could influence the sea-ice distribution (e.g., Kelly et al. 1987) leading to changes in the North Atlantic Deep Water formation (Aagard and Carmack 1989) and thus affect the thermohaline circulation. Indeed, Delworth and Mann (2000) have found observational and modeling evidence of an interdecadal thermohaline circulation signal in the North Atlantic ocean that they interpret as an internal ocean mode excited by a spatially coherent atmospheric forcing.

While providing a clear conceptual interpretation of interdecadal climate variability in mid- 
latitudes, the results from an idealized intermediate coupled model must be treated with caution. However, our model results give a reference null description of the midlatitude lowfrequency variability, which can then be tested against using more complete models.

\section{Acknowledgements}

The discussions of various aspects of this research with Drs. P. Berloff, W. K. Dewar, M. Ghil and J. C. McWilliams were very useful. The manuscript was significantly improved by the constructive comments of the two referees. This research was supported by DOE Grant 98ER6215. This is IGPP publication No. 5746 . 


\section{References}

Aagard K, Carmack EC (1989) The role of sea ice and other fresh water in the Arctic circulation. J Geophys Res 94:14,485-14,498.

Berloff P, McWilliams JC (1999) Large-scale, low-frequency variability in wind-driven ocean gyres. J Phys Oceanogr 29:1925-1949.

Berloff P, Meacham S (1997) The dynamics of an equivalent-barotropic model of the winddriven circulation. J Mar Res 55:407-451.

Berloff P, Meacham S (1998) The dynamics of a simple baroclinic model of the wind-driven circulation. J Phys Oceanogr 28:361-388.

Bjerknes J (1964) Atlantic air-sea interaction. Advances in Geophysics 10:1-82.

Budyko MI (1969) The effect of solar radiation variations on the climate of the Earth. Tellus 21:611-619.

Cessi P (2000) Thermal feedback on wind stress as a contributing cause of climate variability. J Climate 13:232-244.

Cessi P, Ierley G (1995) Symmetry breaking multiple equilibria in quasigeostrophic wind-driven flows. J Phys Oceanogr 25:1196-1205.

Danabasoglu G (1998) On the wind-driven circulation of the uncoupled and coupled NCAR climate system ocean model. J Climate 11: 1442-1454.

Delworth TL, Manabe S, Stouffer RJ (1993) Interdecadal variations of the thermohaline circulation in a coupled ocean-atmosphere model. J Climate 6:1993-2011.

Delworth TL, Mann ME (2000) Observed and simulated multidecadal variability in the Northern Hemisphere. Climate Dyn 16:661-676.

Deser C, Blackmon ML (1993) Surface climate variations over the North Atlantic Ocean during winter: 1900-1989. J Climate 6:1743-1753.

Dettinger MD, Ghil M, Strong CM, Weibel W, Yiou P (1995) Software expedites singularspectrum analysis of noisy time series. EOS, Trans AGU 76:12,14,21.

Dewar WK (2001) On ocean dynamics in midlatitude climate. J Climate 14:4380-4397.

Dewar WK (2002) Quasi-geostrophic climate dynamics. J Mar Res (sub judice).

Dijkstra HA, Katsman CA (1997) Temporal variability of the quasigeostrophic wind-driven double gyre ocean circulation: Basic bifurcation diagrams. Geophys Astrophys Fluid Dyn 85:195-232.

Ferranti L, Molteni F, Palmer TN (1994) Impact of localized tropical and extratropical SST anomalies in ensembles of seasonal GCM integrations. QJR Meteorol Soc 120:1613-1645. 
Ghil M, Feliks Y, Sushama L (2002) Baroclinic and barotropic aspects of the wind-driven ocean circulation. Physica D (accepted).

Greatbatch RJ, Fanning AF, Goulding AD, Levitus S (1991) A diagnosis of interpentadal circulation changes in the North Atlantic. J Geophys Res 96:22,009-22,023.

Grötzner A, Latif M, Barnett TP (1998) A decadal climate cycle in the North Atlantic Ocean as simulated by ECHO coupled GCM. J Climate 11:831-847.

Haidvogel D, McWilliams JC, Gent P (1992) Boundary current separation in a quasigeostrophic, eddy-resolving ocean circulation model. J Phys Oceanogr 22:882-902.

Haney RL (1971) Surface thermal boundary conditions for ocean circulation models. J Phys Oceanogr 1:241-248.

Held IM (1983) Stationary and quasi-stationary eddies in the extratropical troposphere: Theory. In: Hoskins BJ, Pierce RP (eds) Large-Scale Dynamical Processes in the Atmosphere, Academic Press, pp 127-168.

Ierley G, Sheremet V (1995) Multiple solutions and advection-dominated flows in the winddriven circulation. Part I: Slip. J Mar Res 53:703-737.

James IN, James PM (1989) Ultra-low frequency variability in a simple atmospheric circulation model. Nature 342:53-55.

Jin F-F (1997) A theory of interdecadal climate variability of the North Pacific oceanatmosphere system. J Climate 10:1821-1835.

Kelly PM, Goodess CM, Cherry BSG (1987) The interpretation of the Icelandic sea ice record. J Geophys Res 92:10,835-10,843.

Koo S (2001) Nonlinear aspects of atmospheric zonal-flow vacillation. PhD Thesis, University of California, Los Angeles, 163pp.

Krahmann G, Visbeck M, Reverdin G (2001) Formation and propagation of temperature anomalies along the North Atlantic Current. J Phys Oceanogr 31:1287-1303.

Kravtsov SV, Robertson AW, Ghil M (2001) Low-frequency variability in a baroclinic betachannel with land-sea contrast. J Atmos Sci (submitted). An electronic version of the paper is available at www.atmos.ucla.edu/tcd/MG/sergey.html

Kushnir Y (1994) Interdecadal variations in North Atlantic sea surface temperature and associated atmospheric conditions. J Climate 7:141-157.

Kushnir Y, Held I (1996) Equilibrium atmospheric response to North Atlantic SST anomalies. J Climate 7:141-157.

Kushnir Y, Lau NC (1992) The general circulation model response to a North Pacific SST anomaly: Dependence on time scale and pattern polarity. J Climate 5:271-283.

Latif M, Barnett TP (1994) Causes of decadal climate variability in the North Pacific/North American sector. Science 266:634-637. 
Latif M, Barnett TP (1996) Decadal climate variability over the North Pacific and North America: Dynamics and predictability. J Climate 9:2407-2423.

Levitus S (1989a) Interpentadal variability of temperature and salinity at intermediate depths of the North Atlantic Ocean, 1970-1974 versus 1955-1959. J Geophys Res 94:6091-6131.

Levitus S (1989b) Interpentadal variability of salinity in the upper $150 \mathrm{~m}$ of the North Atlantic Ocean, 1970-1974 versus 1955-1959. J Geophys Res 94:9679-9685.

Liu Z (1993) Interannual positive feedbacks in a simple extratropical air-sea coupling system. J Atmos Sci 50:3022-3028.

Mann ME, Lees JM (1996) Robust estimation of background noise and signal detection in climatic time series. Clim Change 33:409-445.

Marotzke J, Pierce DW (1997) On spatial scales and lifetimes of SST anomalies beneath a diffusive atmosphere. J Phys Oceanogr 27:133-139.

Meacham S, Berloff P (1997a) Barotropic, wind-driven circulation in a small basin. J Mar Res 55:523-563.

Meacham S, Berloff P (1997b) Instabilities of a steady, wind-driven circulation. J Mar Res 55:885-913.

Mehta VM, Suarez MJ, Manganello JV, Delworth TL (2000) Oceanic influence on the North Atlantic Oscillation and associated Northern Hemisphere climate variations: 1959-1993. Geoph Res Letts 27:121-124.

Münnich M, Latif M, Venske S, Maier-Reimer E (1998) Decadal oscillations in a simple coupled model. J Climate 11:3309-3319.

North GR, Cahalan RF, Coakley JA Jr (1981) Energy balance climate models. Rev Geophys Space Phys 19:91-121.

Otnes R, Enochson L (1978) Applied time series analysis. Vol. I, Wiley and Sons, 449 pp.

Pedlosky J (1987) Geophysical fluid dynamics. Springer, New York, 621 pp.

Peng S, Mysak LA, Ritchie H, Derome J, Dugas B (1995) The differences between early and middle winter atmospheric response to sea surface temperature anomalies in the northwest Atlantic. J Climate 8:137-157.

Peng S, Robinson WA, Hoerling MP (1997) The modeled atmospheric response to midlatitude SST anomalies and its dependence on background circulation states. J Climate 10:971-987.

Qiu B (2000) Interannual variability of the Kuroshio extension system and its impact on the wintertime SST field. J Phys Oceanogr 30:1486-1502.

Robertson AW (1996) Interdecadal variability over the North Pacific in a multi-century climate simulation. Climate Dyn 12:227-241. 
Robertson AW (2001) Influence of ocean-atmosphere interaction on the Arctic Oscillation in two general circulation models. J Climate 14:3240-3254.

Rodwell MJ, Rodwell DP, Folland CK (1999) Oceanic forcing of the wintertime North Atlantic Oscillation and European climate. Nature 398:320-323.

Saravanan R (1998) Atmospheric low-frequency variability and its relationship to midlatitude SST variability: Studies using NCAR Climate System Model. J Climate 11:165-188.

Saravanan R, Danabasoglu G, Doney SC, McWilliams JC (2000) Decadal variability and predictability in midlatitude ocean-atmosphere system. J Climate 13:1073-1097.

Schneider N, Miller AJ, Pierce DW (2002) Anatomy of North Pacific decadal variability. J Climate (in press).

Speich S, Dijkstra H, Ghil M (1995) Successive bifurcations in a shallow-water model applied to the wind-driven ocean circulation. Nonlin Proc Geophys 2:241-268.

Spall MA (1996) Dynamics of the Gulf Stream/Deep Western Boundary Current crossover. Part II: Low-frequency internal oscillations. J Phys Oceanogr 26:2169-2182.

Stephens GL, Campbell GG, Vonder Haar TH (1981) Earth radiation budgets. J Geophys Res $86: 9,739-9,760$.

Vautard R, Legras B, Deque M (1988) On the source of midlatitude low-frequency variability. Part I: A statistical approach to persistence. J Atmos Sci 45:2811-2843.

von Storch JS (1994) Interdecadal variability in a global coupled model. Tellus 46A:419-436.

Wallace JM, Smith C, Jiang Q (1990) Spatial patterns of atmosphere-ocean interaction in the northern winter. J Climate 3:990-998.

Wang W-C, Stone PH (1980) Effect of ice-albedo feedback on global sensitivity in a onedimensional radiative-convective climate model. J Atmos Sci 37:545-552.

Weng W, Neelin JD (1998) On the role of ocean-atmosphere interaction in midlatitude decadal variability. Geophys Res Letts 25:167-170.

Xie S-P, Kunitani T, Kubokawa A, Nonaka M, Hosoda S (2000) Interdecadal thermocline variability in the North Pacific for 1958-97: A GCM simulation. J Phys Oceanogr 30:27982813 . 


\section{FIGURE CAPTIONS}

Fig. 1: Model geometry, see text.

Fig. 2: Time-mean zonally averaged barotropic zonal wind from the atmosphere-only integration (A1 of Table 1). Solid line: upper layer; dashed line: lower layer. $y=0$ corresponds to $45^{\circ} N$.

Fig. 3: Atmospheric climatology of the atmosphere-only integration (A1 of Table 1). (a) Time-mean barotropic zonal velocity (contours, every $3 \mathrm{~m} \mathrm{~s}^{-1}$ ); total turbulent eddy kinetic energy (shading, every $20 \mathrm{~m}^{2} \mathrm{~s}^{-2}$ ); (b) time-mean atmospheric temperature (contours, every $3{ }^{\circ} \mathrm{C}$ ); atmospheric temperature variance (shading, every $5 \mathrm{C}^{2}$ ). Heavy line marks oceanic boundaries, small rectangle within the ocean will be referred to in later analyses (see text).

Fig. 4: Leading atmospheric empirical orthogonal function (EOF) of the barotropic streamfunction for the atmosphere-only run (A1 of Table 1), which accounts for $35 \%$ of total variance; contour interval $10^{6} \mathrm{~m}^{2} \mathrm{~s}^{-1}$, negative contours dashed, zero contour omitted.

Fig. 5: Atmospheric power spectrum of the atmosphere-only run (A1 of Table 1), constructed from PC-1 of the barotropic streamfunction. (a) Full spectrum; (b) low-frequency portion. Smooth solid line: red-noise AR(1) fit to the spectrum; dashed line: $90 \%$ confidence level; dotted line: $95 \%$ confidence level.

Fig. 6: Ocean climatology of the ocean-only integration (O1b of Table 1) forced with dailysampled atmospheric time series from the atmosphere-only integration (A1 of Table 1). Later EOF analyses will be performed in the small rectangle within the ocean; negative contours dashed, zero contours omitted. (a) Barotropic transport; contour interval $10 \mathrm{~Sv}$; (b) interface displacement relative to the boundary; contour interval $40 \mathrm{~m}$; (c) SST; contour interval $3{ }^{\circ} \mathrm{C}$.

Fig. 7: Leading oceanic EOFs of the ocean-only stochastically forced integration (O1b of Table 1), constructed using the data within the small rectangle of Fig. 6. Upper panels use raw data in the EOF analysis; 5-year-low-pass filtered data used in the lower panels. (a, d) Barotropic transport (35\% and $50 \%$ of total variance); contour interval $5 \mathrm{~Sv}$; (b, e) internal interface displacement ( $28 \%$ and $63 \%$ of total variance); contour interval $10 \mathrm{~m} ;(\mathrm{c}, \mathrm{f}) \mathrm{SST}(27 \%$ and $44 \%$ of total variance); contour interval $0.2{ }^{\circ} \mathrm{C}$. Negative contours dashed, zero contours omitted. 
Fig. 8: Evolution of the stochastically forced ocean run (O1b of Table 1). Solid line: 5year-low-pass filtered time series of the atmospheric PC-1 (corresponding to the EOF in Fig. 4); dashed line: 5-year-low-pass filtered PC-1 time series of the oceanic interface displacement (corresponding to the EOF in Fig. 7b,e), lagged by 2.75 years.

Fig. 9: Leading basin-scale EOFs for the stochastically forced ocean-only run (O1b of Table 1). (a) Barotropic transport (25\% of total variance); contour interval 5 Sv; (b) interface displacement (34\% of total variance); contour interval $5 \mathrm{~m}$; (c) SST (23\% of total variance); contour interval $0.1{ }^{\circ} \mathrm{C}$; Negative contours dashed, zero contours omitted.

Fig. 10: Atmospheric climatology of the coupled run (CO of Table 1). Details as in Fig. 3.

Fig. 11: Leading atmospheric EOF of the coupled run (CO of Table 1). Details as in Fig. 4; the EOF explains $41 \%$ of total variance.

Fig. 12: Atmospheric power spectrum of the coupled run (CO of Table 1). Details as in Fig. 5; in multi-taper spectrum, 7 tapers are used here rather than 5 tapers used to construct Fig. 5.

Fig. 13: Oceanic climatology of the coupled run (CO of Table 1). Details as in Fig. 6.

Fig. 14: (a) Leading EOF of the ocean interface displacement for the coupled run (CO of Table 1); (34\% of total variance); contour interval is $5 \mathrm{~m}$. Negative contours dashed, zero contour omitted; (b) power spectrum of the PC corresponding to the EOF in panel (a).

Fig. 15: Leading oceanic EOFs of the coupled run (CO of Table 1), using 200-day-binned data (upper panels) and 5-year-low-pass filtered data (lower panels). (a, c) EOF-1 of the barotropic transport (26\% and $58 \%$ of total variance); contour interval $2 \mathrm{~Sv}$; (b) EOF-2 of the interface displacement (26\% of total variance); (e) EOF-1 of the interface displacement ( $42 \%$ of total variance); contour interval $5 \mathrm{~m}$; (c, f) EOF-1 of SST (24\% and 35\% of total variance); contour interval $0.1{ }^{\circ} \mathrm{C}$. Negative contours dashed, zero contour omitted.

Fig. 16: Leading EOF of SST obtained in the different versions of the mixed layer integration (see text). Contour interval $0.03{ }^{\circ} \mathrm{C}$. (a) Full mixed layer model; (b) no forcing by the anomalous atmospheric temperature; (c) only the advection of the mean SST by the anomalous baroclinic current is included; (d) only the advection of the mean SST by the anomalous barotropic current is included. 


\begin{tabular}{|l|l|}
\hline \multicolumn{1}{|c|}{ Experiment } & \multicolumn{1}{c|}{ Forcing } \\
\hline \hline A1 (atmosphere-only) & fixed SST according to (14) \\
\hline O1a (ocean-only) & atmospheric climatology of A1 \\
\hline O1b ("control" or "idealized" ocean-only) & atmospheric history of A1 \\
\hline CO (coupled) & fully coupled experiment \\
\hline A2 (atmosphere-only) & SST climatology of CO \\
\hline O2a (ocean-only) & atmospheric climatology of CO \\
\hline O2b ("additional" or "adjusted" ocean-only) & atmospheric history of CO \\
\hline A3 (atmosphere-only) & climatological SST + leading SST anomaly of CO \\
\hline
\end{tabular}

TABLE 1. Summary of the experiments 

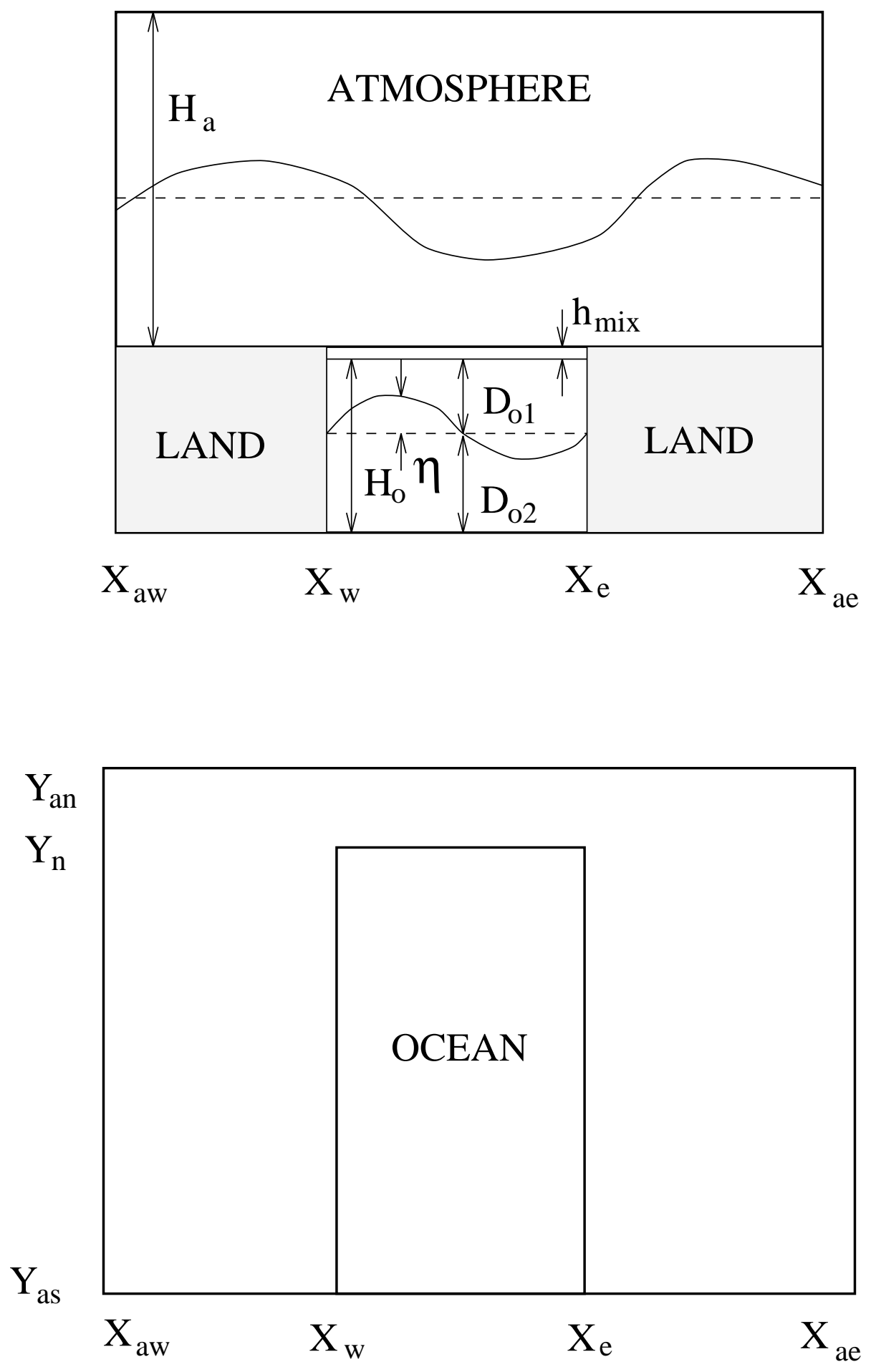

Figure 1: 


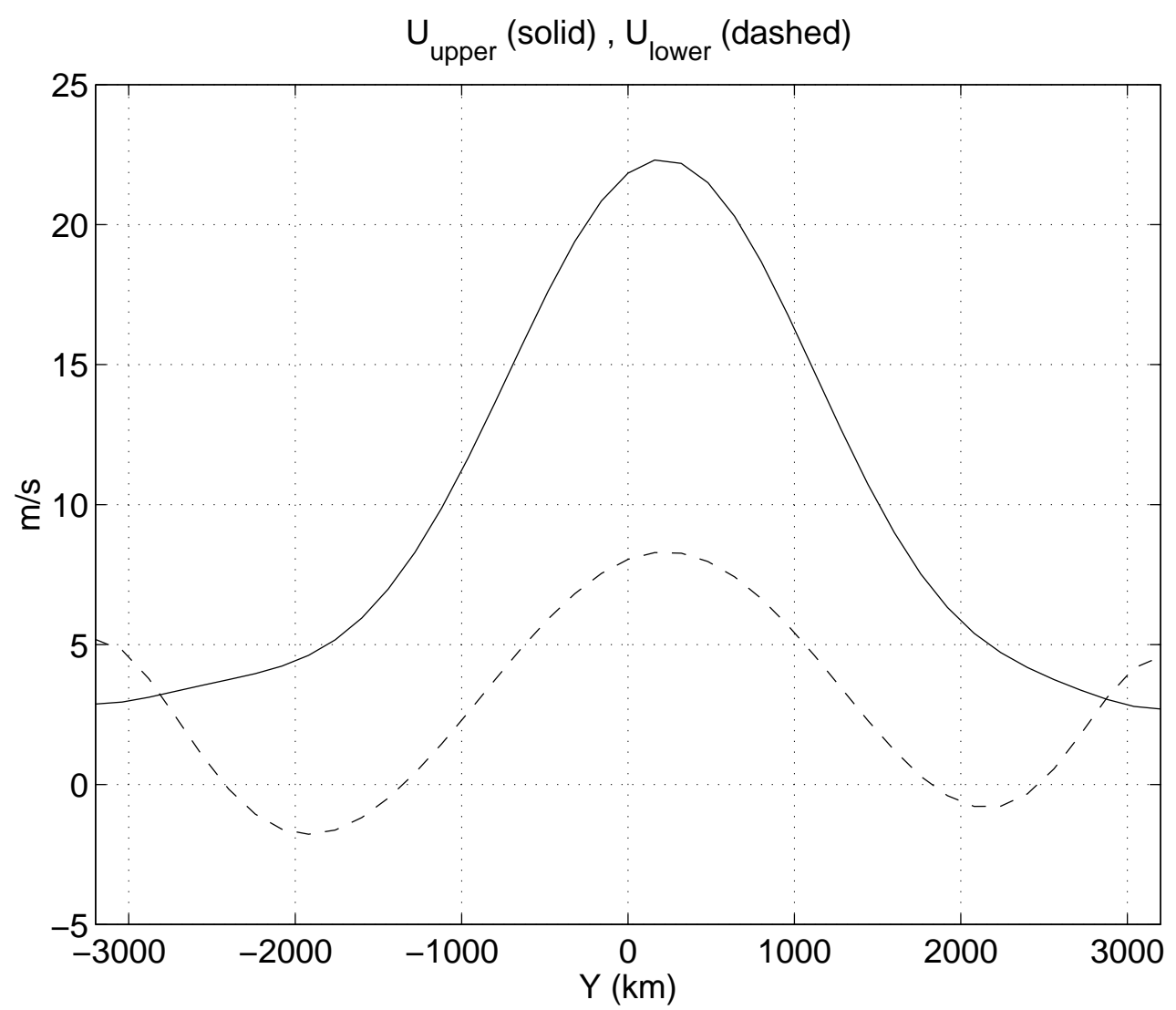

Figure 2: 

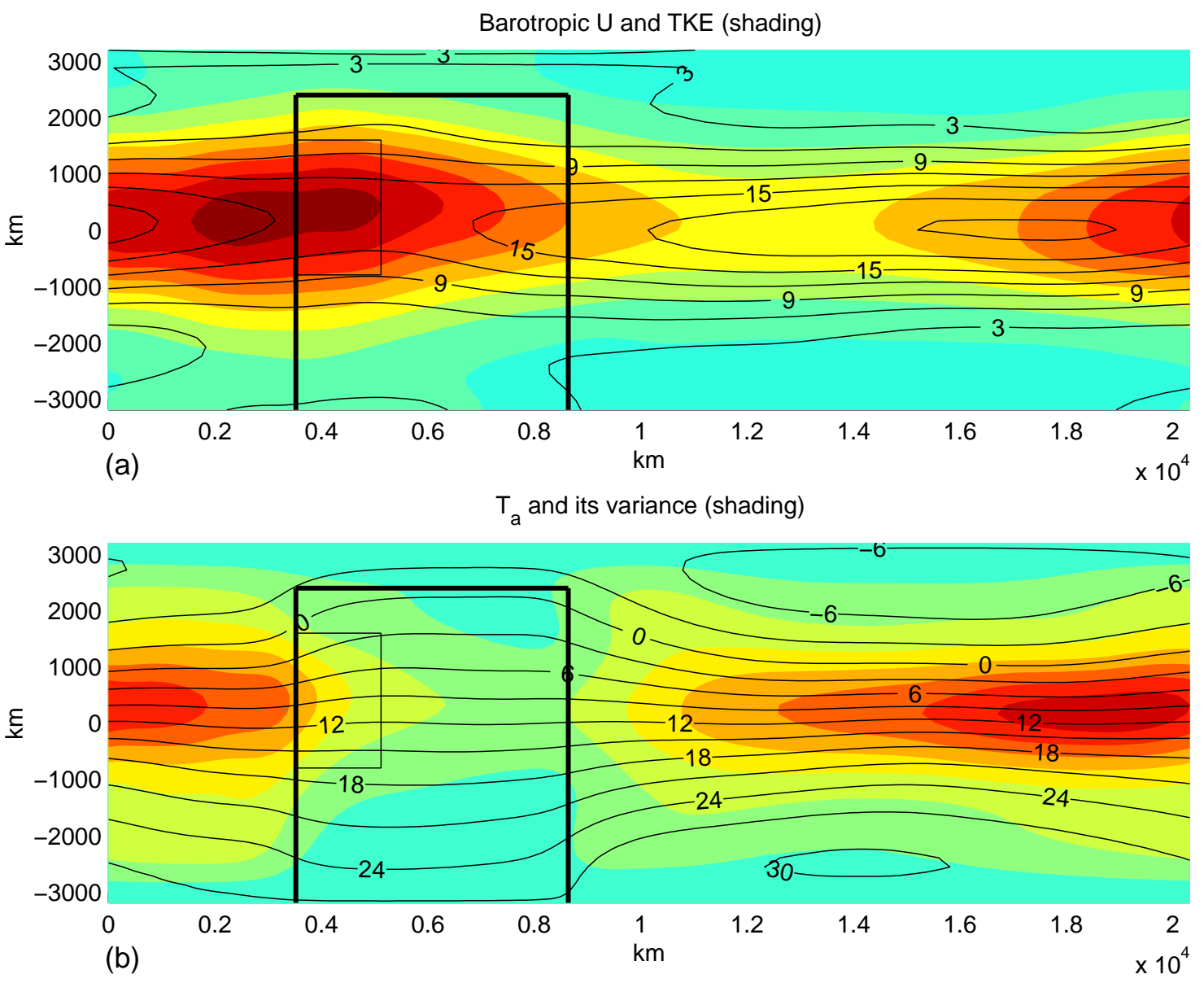

Figure 3: 


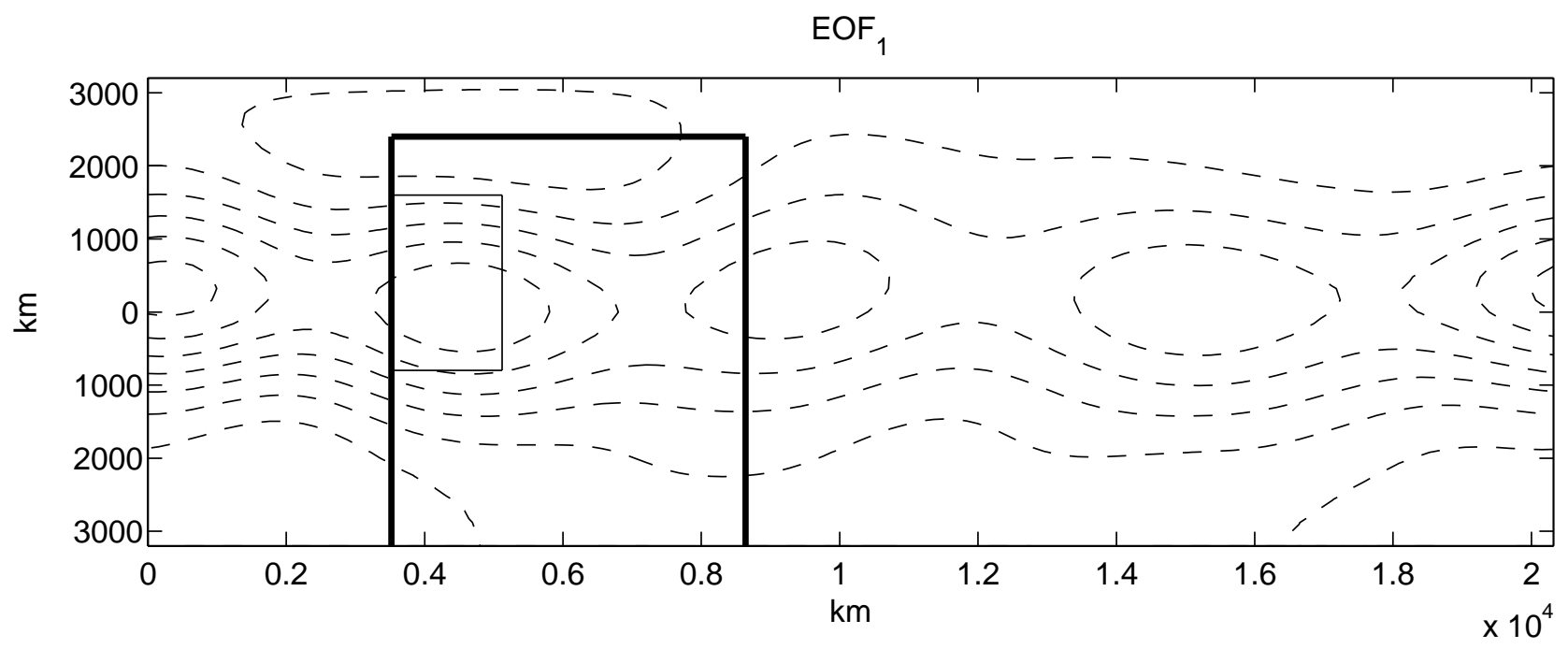

Figure 4: 

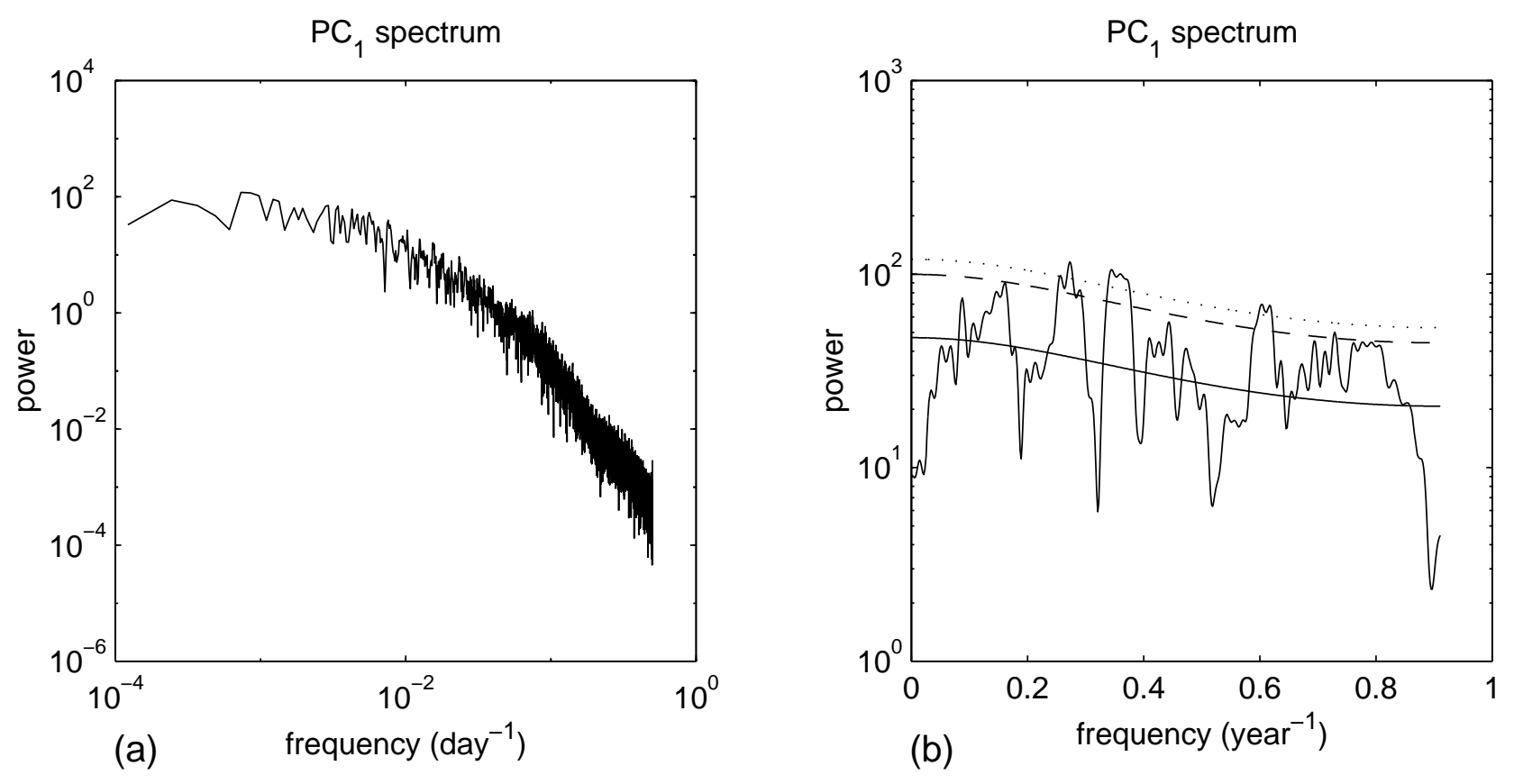

Figure 5: 


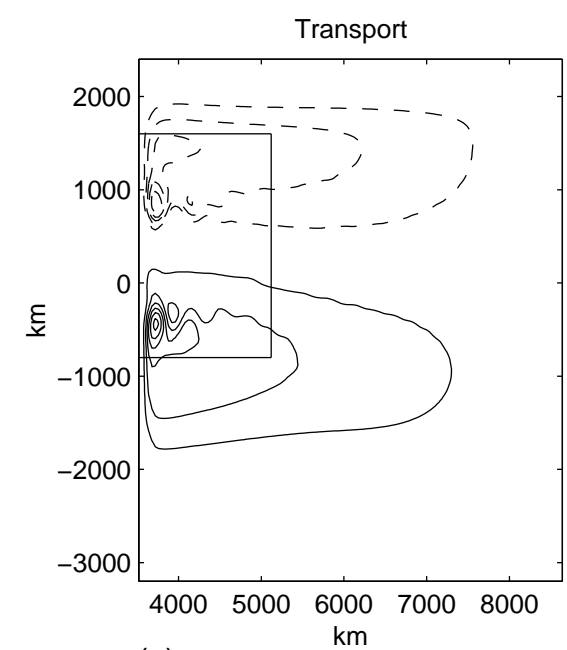

(a)

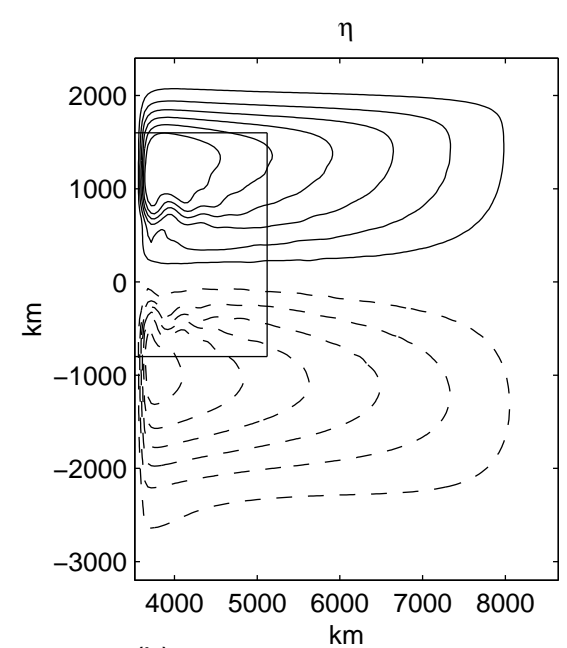

(b)

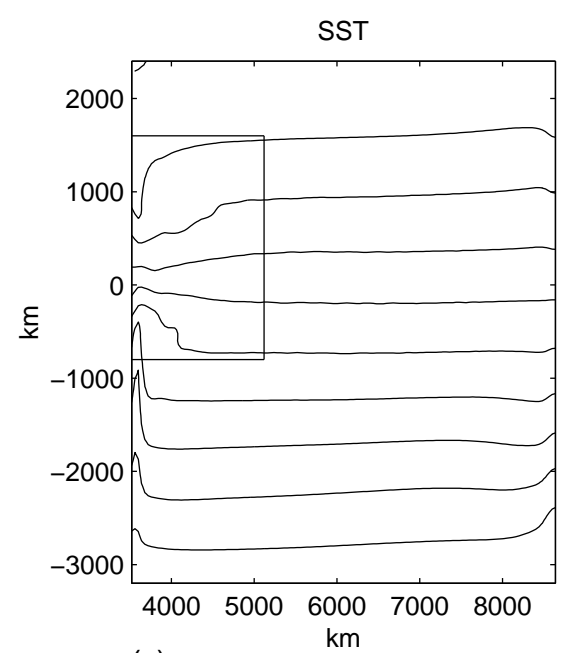

(c)

Figure 6: 


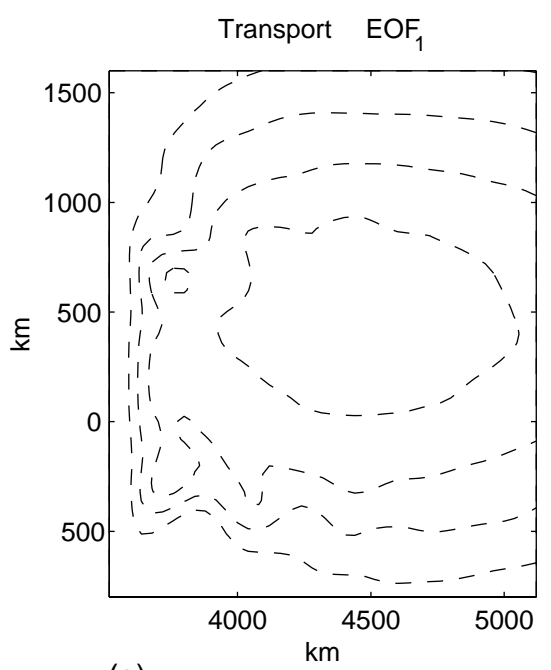

(a)

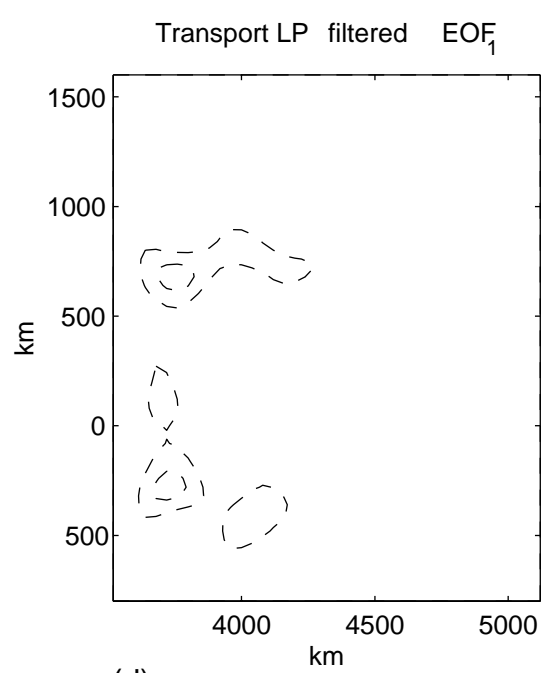

(d)

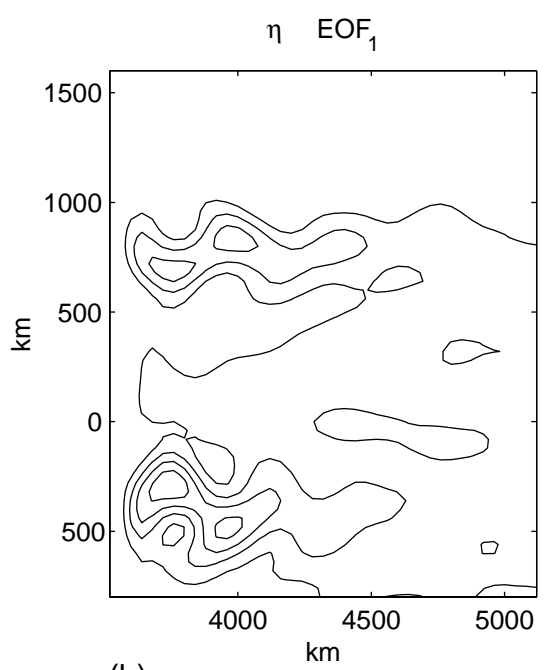

(b)

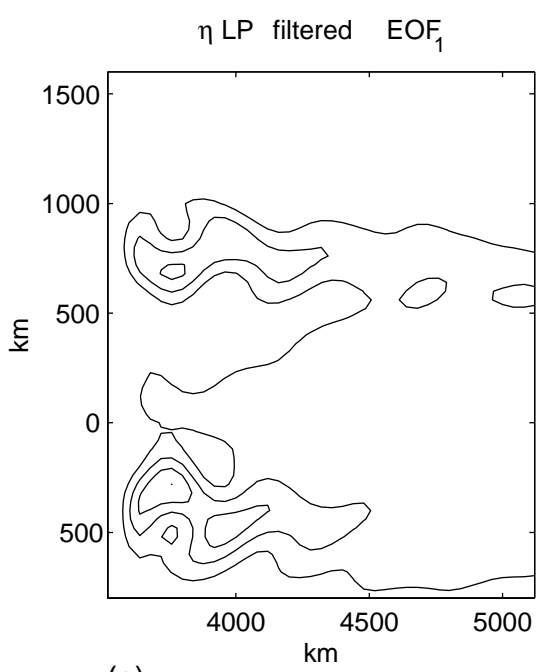

(e)

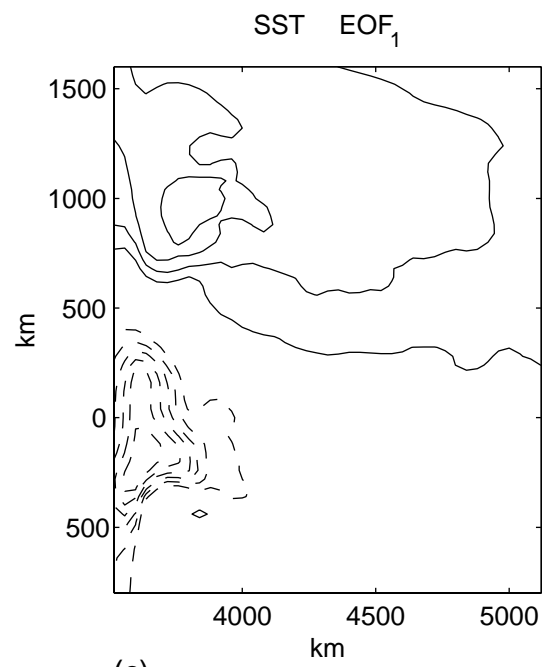

(c)

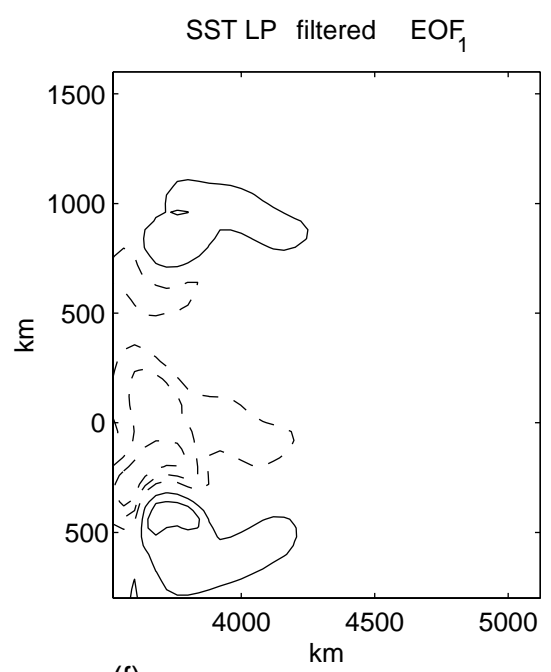

(f)

Figure 7: 


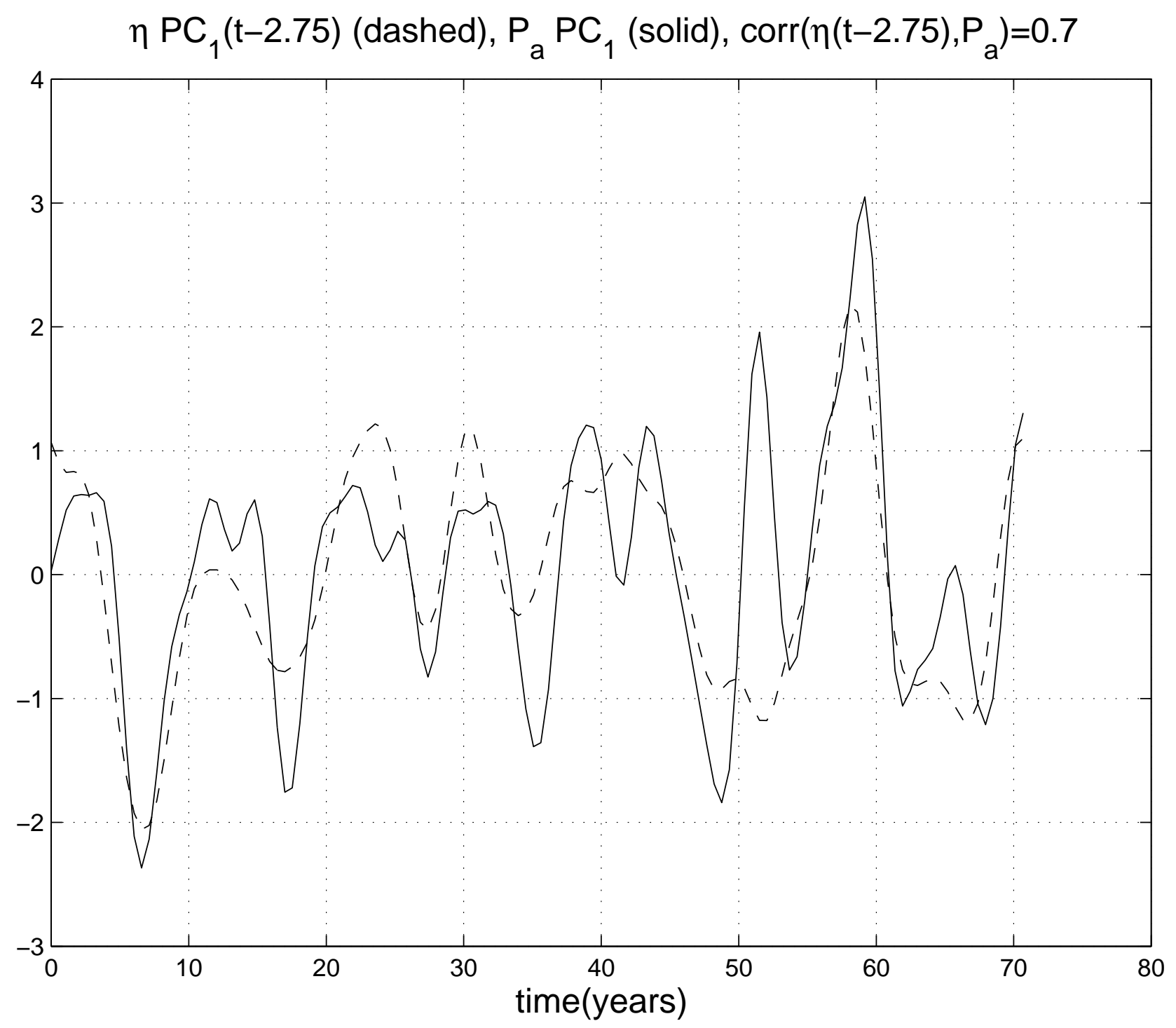

Figure 8: 


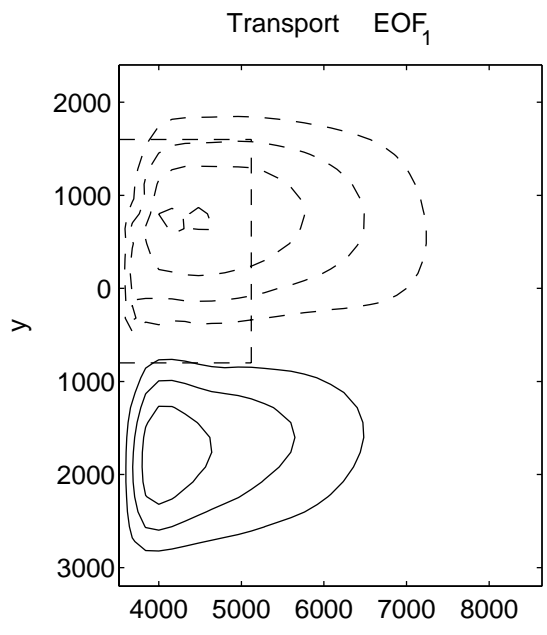

(a)

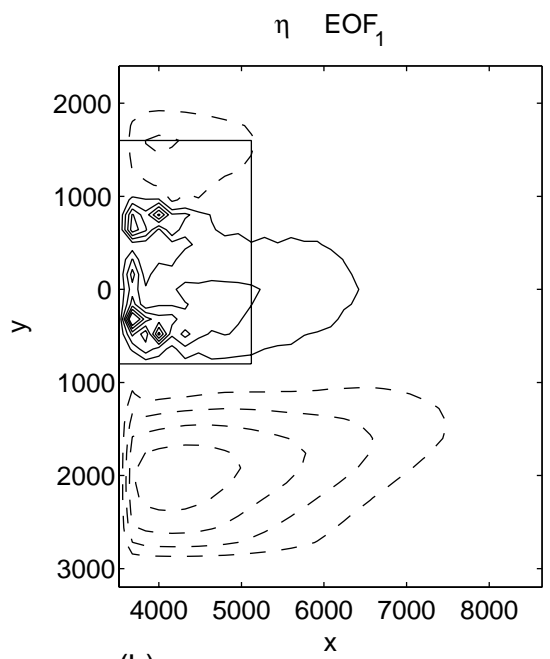

(b)

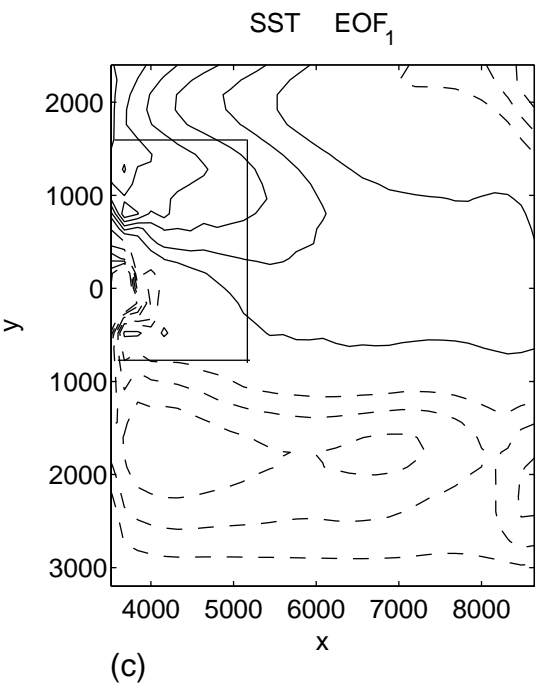

(c)

Figure 9: 
Barotropic $U$ and TKE (shading)
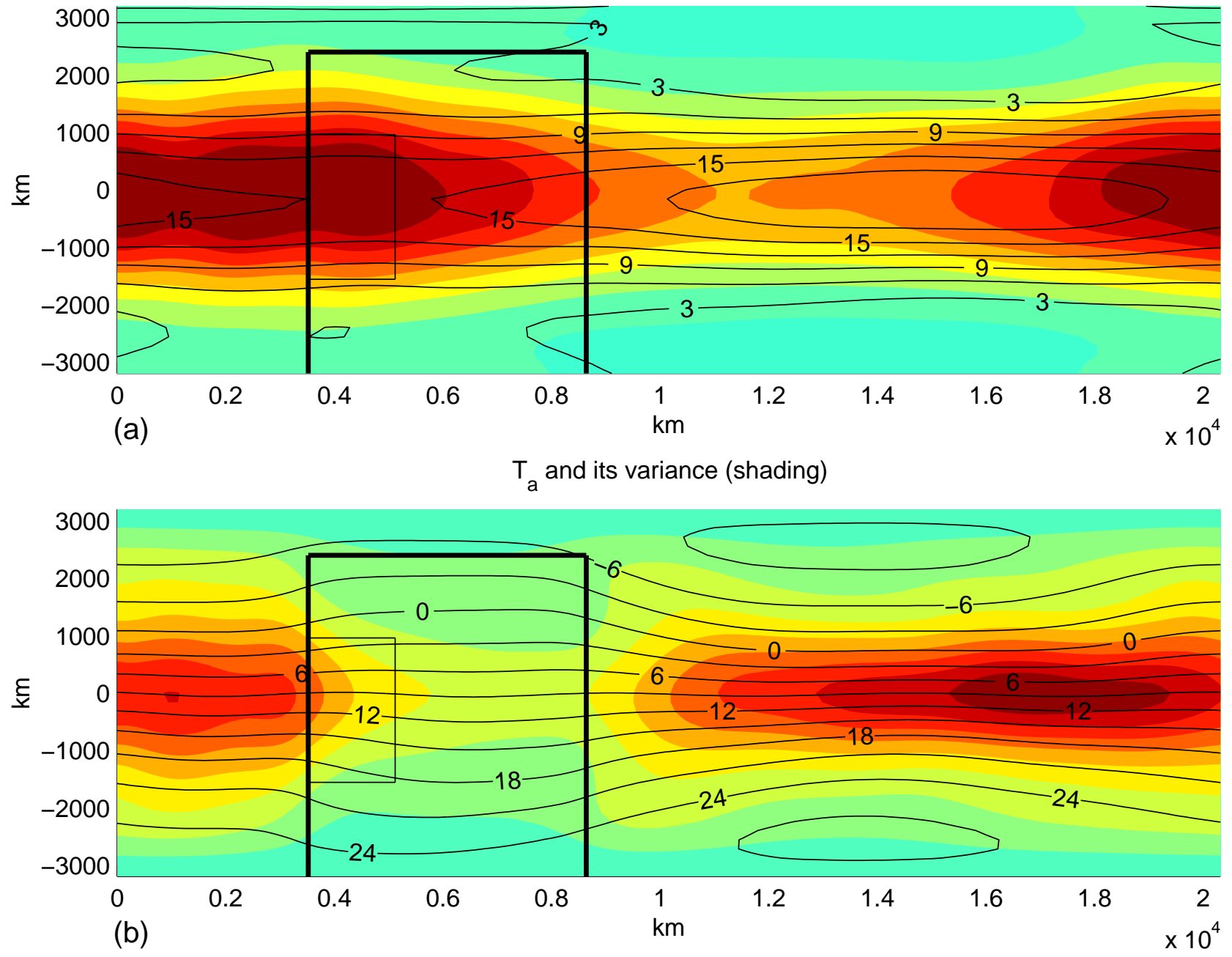

Figure 10: 


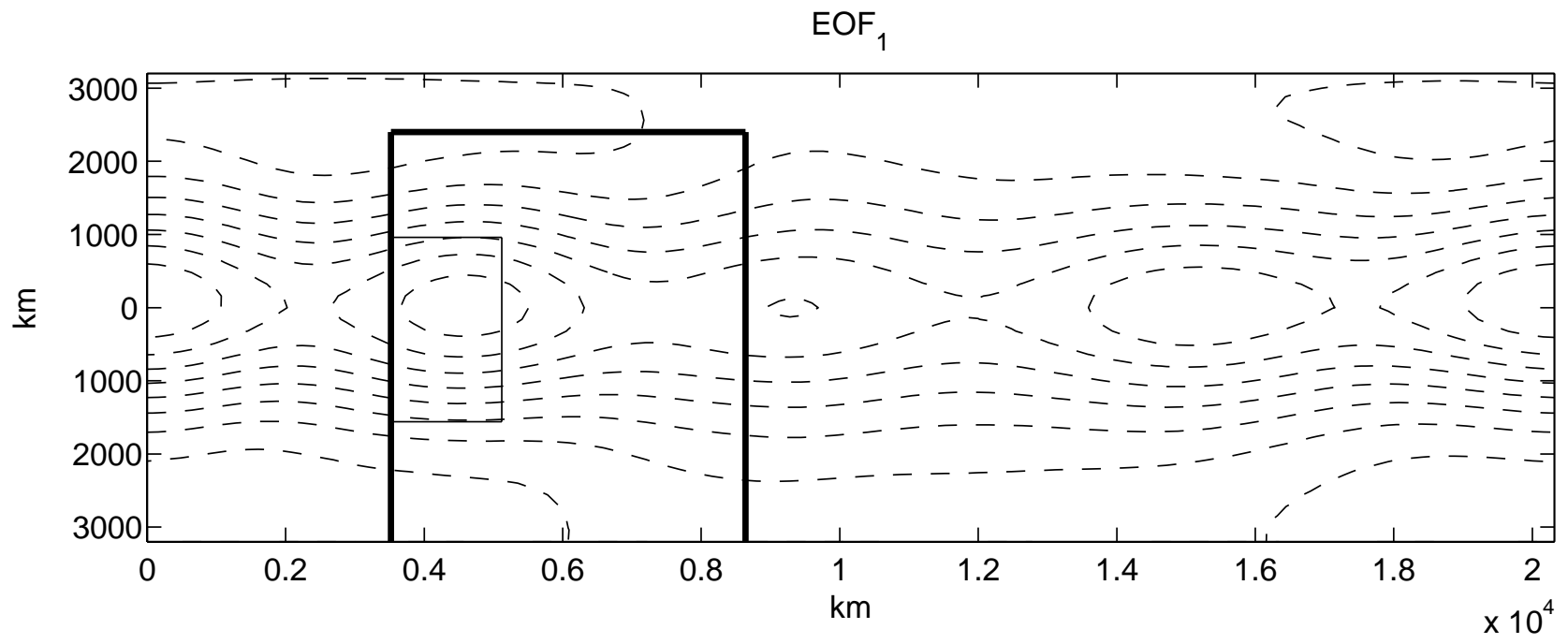

Figure 11: 

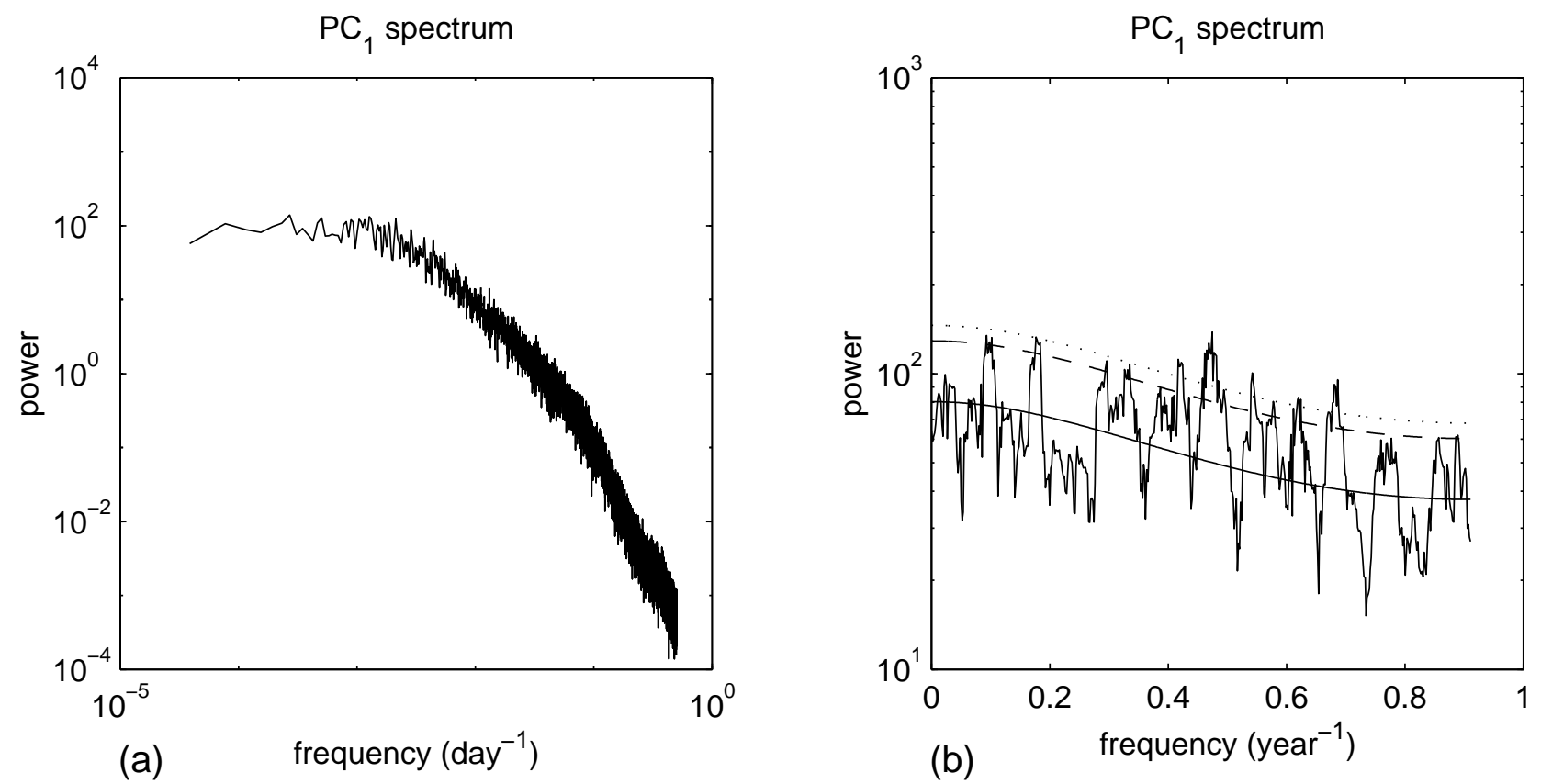

Figure 12: 


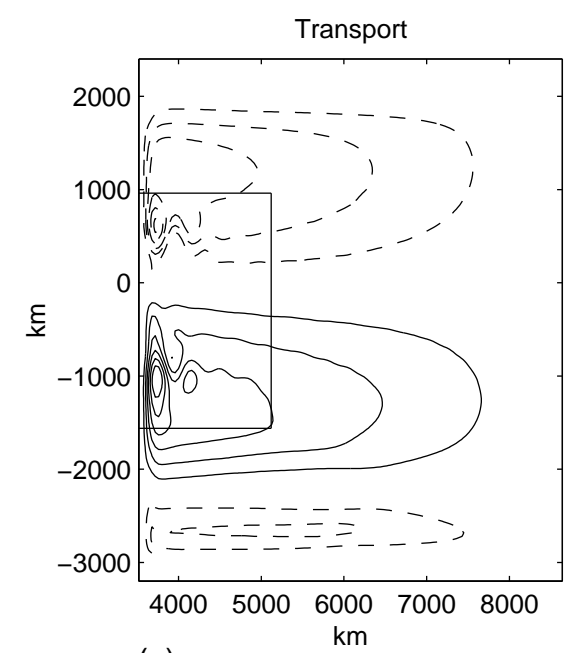

(a)

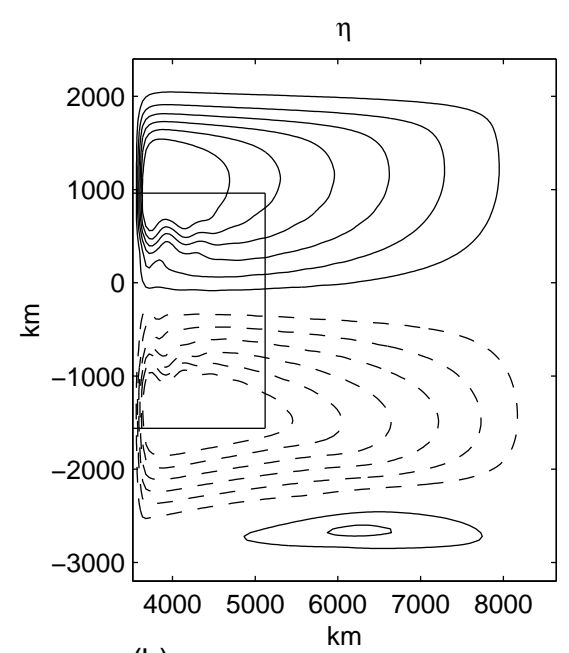

(b)

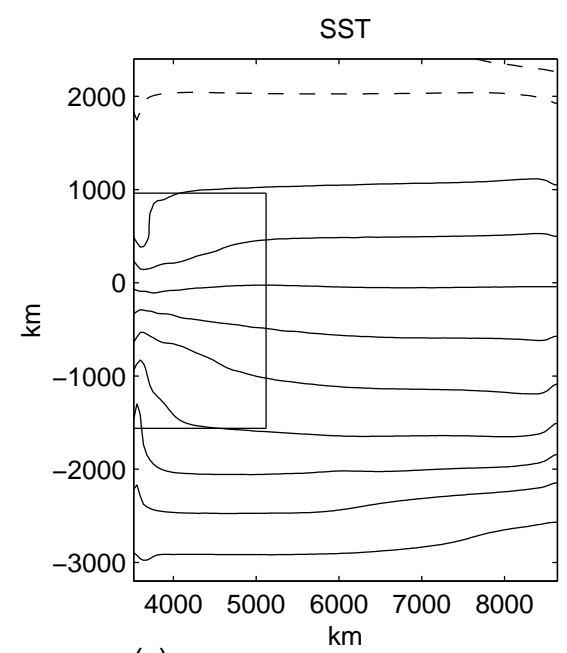

(c)

Figure 13: 

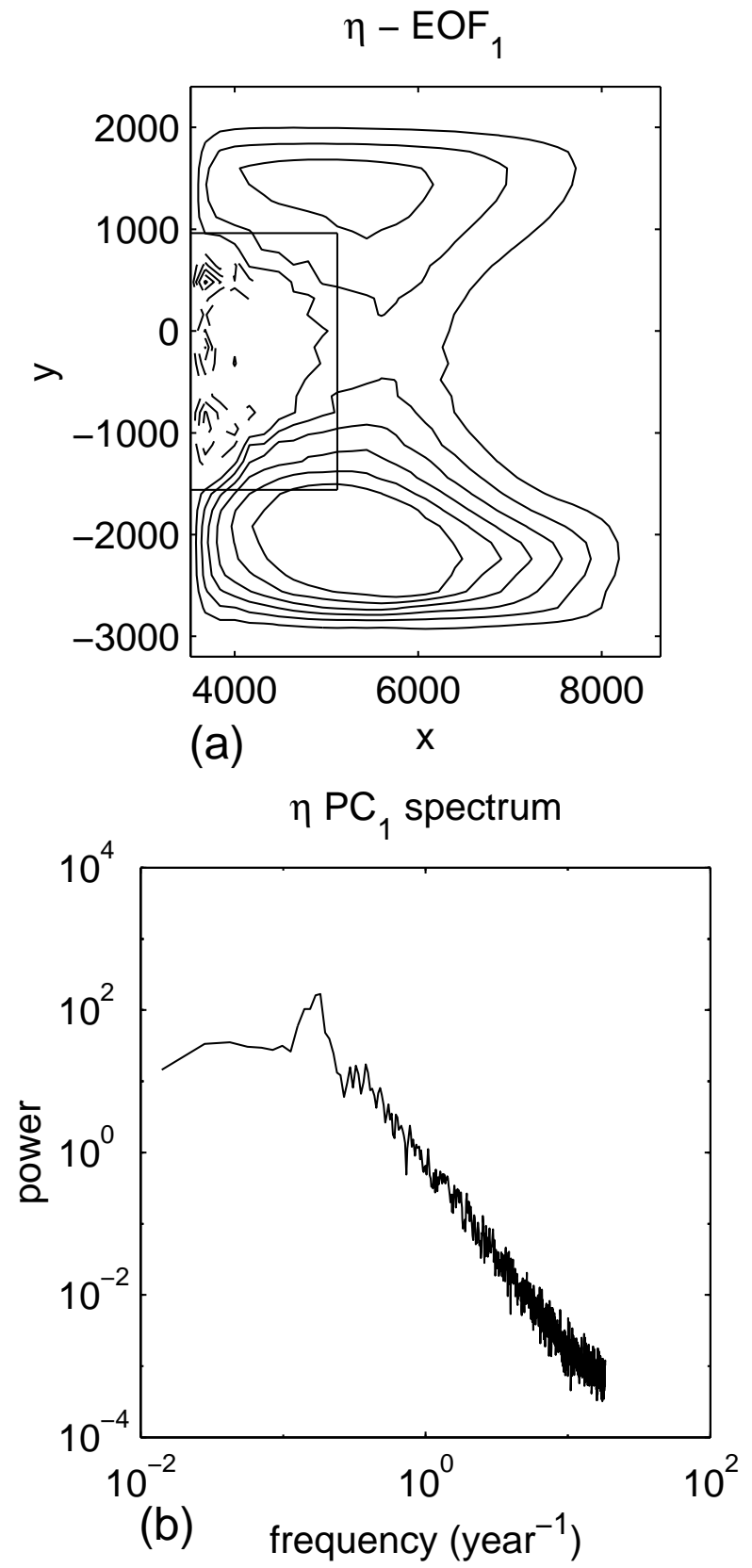

Figure 14: 


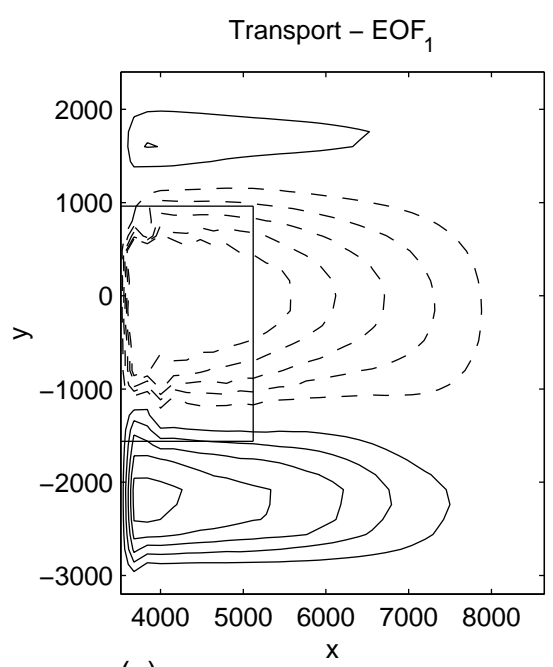

(a)

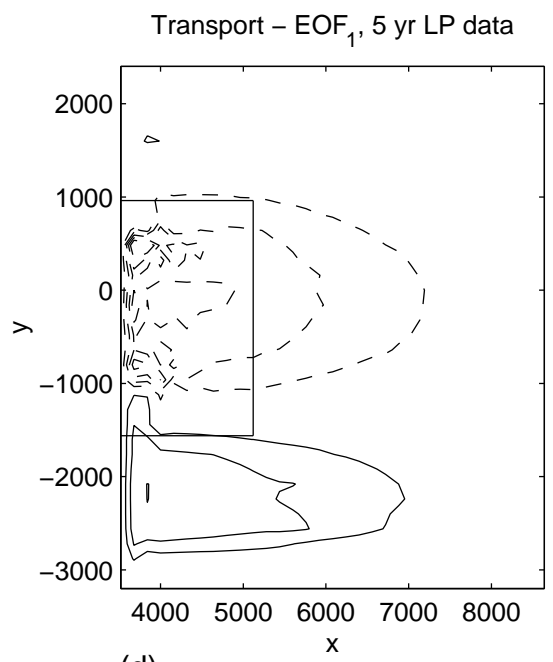

(d)

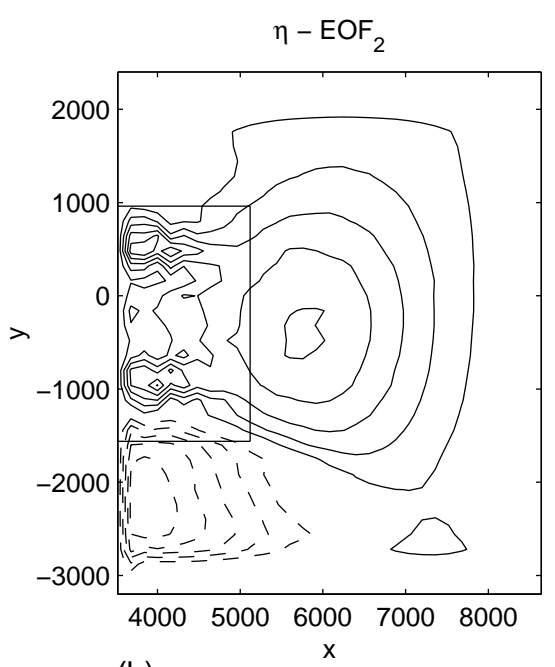

(b)

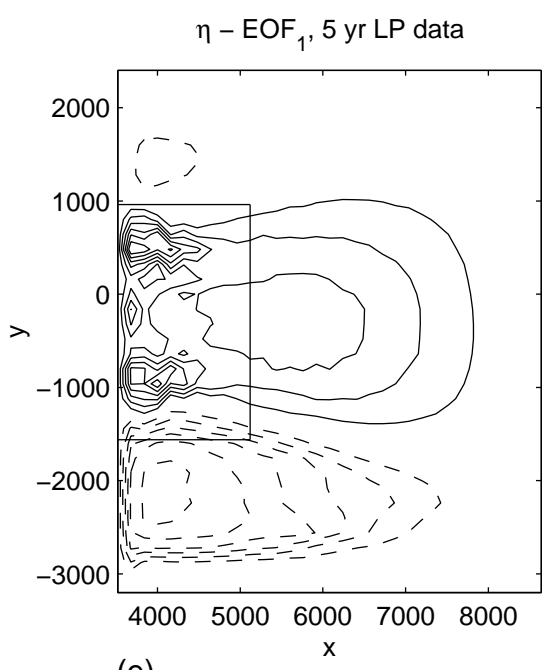

(e)

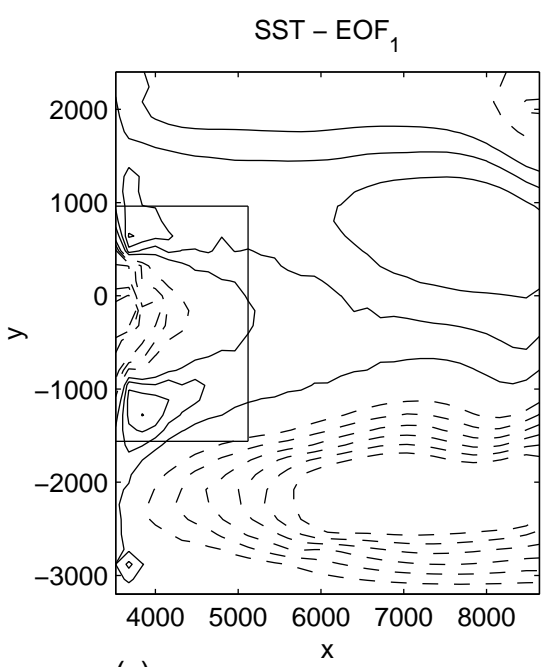

(c)

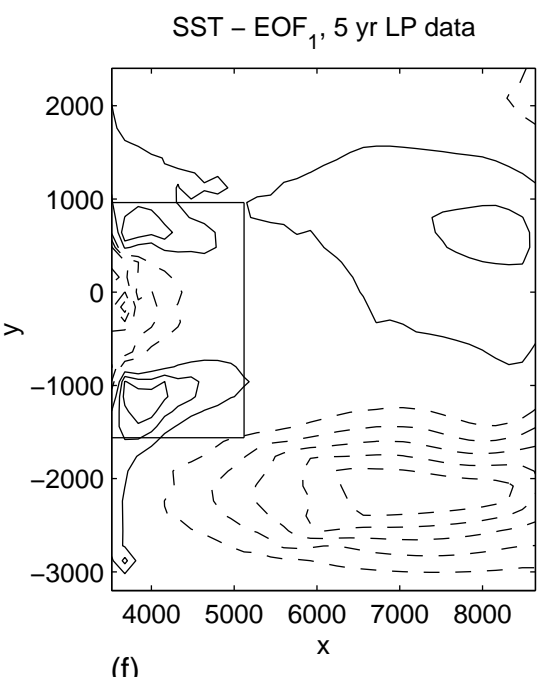

(f)

Figure 15: 


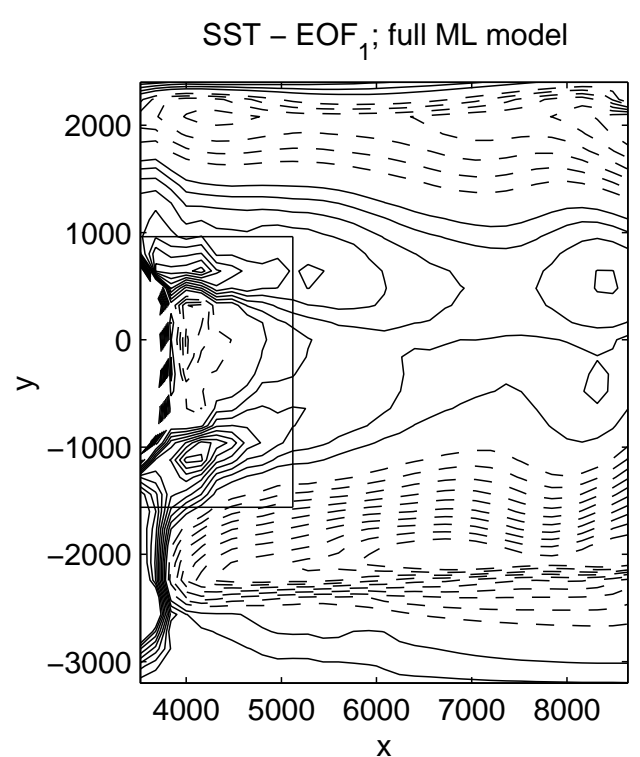

(a)

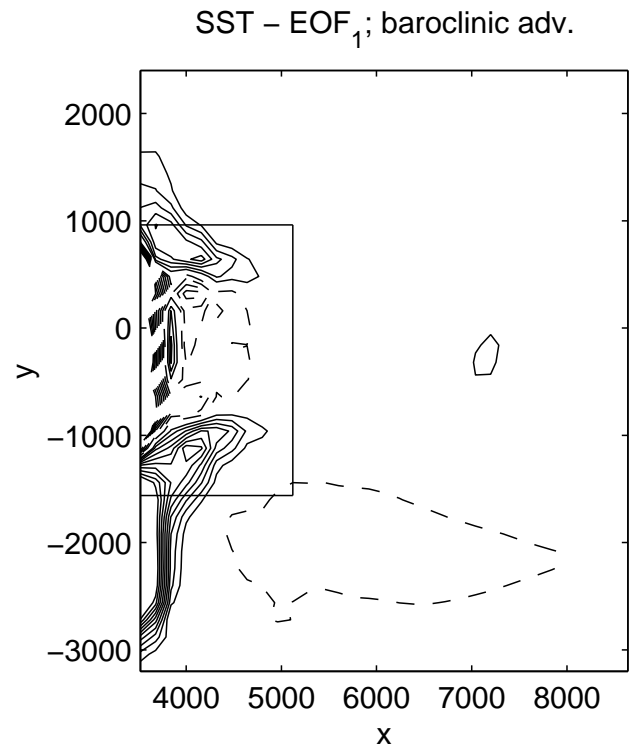

(c)

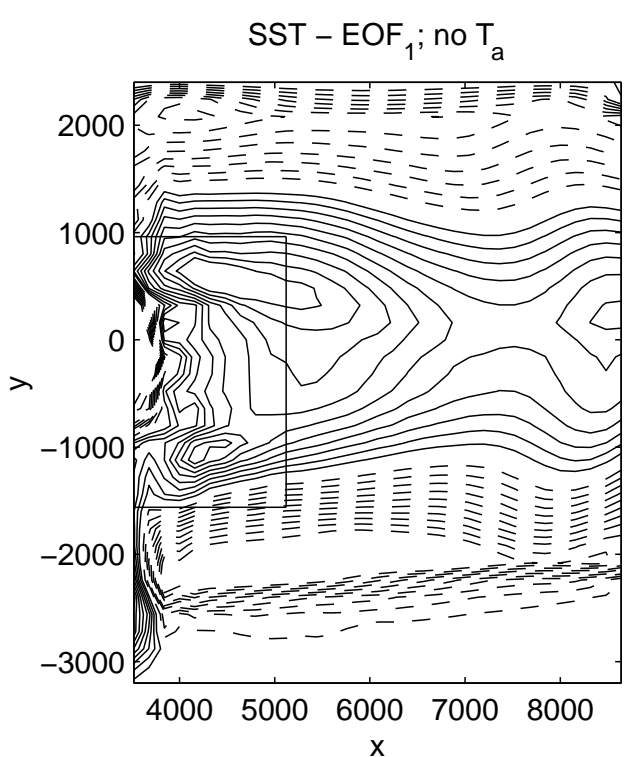

(b)

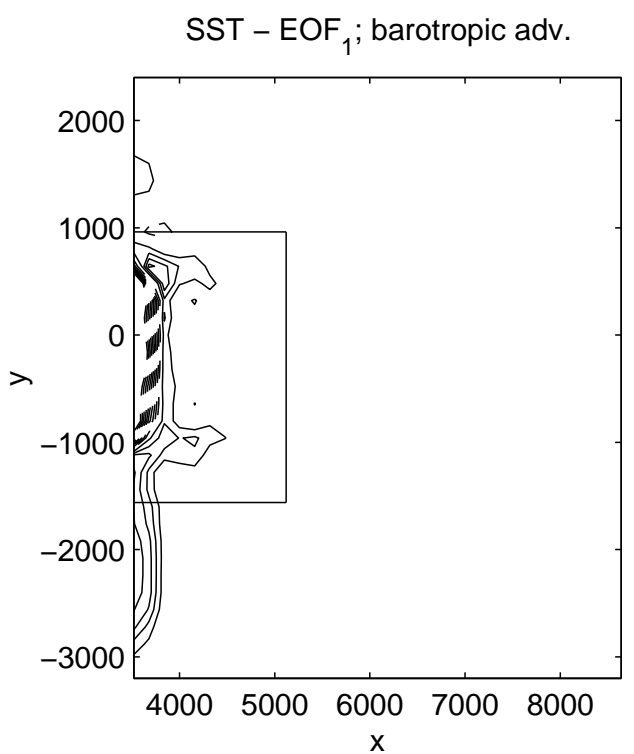

(d)

Figure 16: 